NBER WORKING PAPER SERIES

\title{
HEALTHCARE EXCEPTIONALISM? PERFORMANCE AND ALLOCATION IN THE U.S. HEALTHCARE SECTOR
}

\author{
Amitabh Chandra \\ Amy Finkelstein \\ Adam Sacarny \\ Chad Syverson \\ Working Paper 21603 \\ http://www.nber.org/papers/w21603 \\ NATIONAL BUREAU OF ECONOMIC RESEARCH \\ 1050 Massachusetts Avenue \\ Cambridge, MA 02138 \\ October 2015
}

This paper presents entirely new research based off earlier work released as NBER Working Paper 19200. We are grateful to Daron Acemoglu, Nick Bloom, Iain Cockburn, Chris Conlon, Angus Deaton, Mark Duggan, Joe Doyle, Liran Einav, Matthew Gentzkow, Michael Greenstone, Jonathan Gruber, Ben Olken, Jonathan Skinner, Doug Staiger, Scott Stern, Heidi Williams, numerous seminar participants, and to Maurice Dalton and Nivedhitha Subramanian for expert research assistance. We gratefully acknowledge[funding from the National Institute on Aging: P01 AG005842 and P01 AG019783 (Chandra), R01 AG032449 (Finkelstein) and T32-AG000186 (Sacarny). The views expressed herein are those of the authors and do not necessarily reflect the views of the National Bureau of Economic Research.

At least one co-author has disclosed a financial relationship of potential relevance for this research. Further information is available online at http://www.nber.org/papers/w21603.ack

NBER working papers are circulated for discussion and comment purposes. They have not been peerreviewed or been subject to the review by the NBER Board of Directors that accompanies official NBER publications.

(C) 2015 by Amitabh Chandra, Amy Finkelstein, Adam Sacarny, and Chad Syverson. All rights reserved. Short sections of text, not to exceed two paragraphs, may be quoted without explicit permission provided that full credit, including $(\mathcal{C}$ notice, is given to the source. 
Healthcare Exceptionalism? Performance and Allocation in the U.S. Healthcare Sector Amitabh Chandra, Amy Finkelstein, Adam Sacarny, and Chad Syverson

NBER Working Paper No. 21603

October 2015

JEL No. D22,D24,I11

\section{ABSTRACT}

The conventional wisdom in health economics is that idiosyncratic features of the healthcare sector leave little scope for market forces to allocate consumers to higher performance producers. However, we find robust evidence across a variety of conditions and performance measures that higher quality hospitals tend to have higher market shares at a point in time and expand more over time. Moreover, we find that the relationship between performance and allocation is stronger among patients who have greater scope for hospital choice, suggesting a role for patient demand in allocation in the hospital sector. Our findings suggest that the healthcare sector may have more in common with "traditional" sectors subject to standard market forces than is often assumed.

\author{
Amitabh Chandra \\ John F. Kennedy School of Government \\ Harvard University \\ 79 JFK Street \\ Cambridge, MA 02138 \\ and NBER \\ amitabh_chandra@harvard.edu \\ Amy Finkelstein \\ Department of Economics, E17-228 \\ MIT \\ 77 Massachusetts Avenue \\ Cambridge, MA 02139 \\ and NBER \\ afink@mit.edu
}

\author{
Adam Sacarny \\ Harvard University \\ 1730 Cambridge Street \\ Cambridge, MA 02138 \\ sacarny@ rwj.harvard.edu \\ Chad Syverson \\ University of Chicago \\ Booth School of Business \\ 5807 S. Woodlawn Ave. \\ Chicago, IL 60637 \\ and NBER \\ chad.syverson@chicagobooth.edu
}

An online appendix is available at:

http://www.nber.org/data-appendix/w21603 


\section{Introduction}

A classic "signpost of competition" in manufacturing industries is that higher productivity producers are allocated greater market share at a point in time and over time. The conventional wisdom in the healthcare sector, however, is that idiosyncratic, institutional features of this sector dull or eliminate these competitive reallocation forces. Oft-cited culprits include uninformed consumers who lack knowledge of the quality and price differences across providers; generous health insurance that insulates consumers from the direct financial consequences of their healthcare consumption decisions; and public sector reimbursement that provides little incentive for providers to achieve productive efficiency. These factors are widely believed to dampen the disciplining force of demand-side competition that exists in most other sectors. Echoing and advancing this view, Cutler (2010) notes:

"There are two fundamental barriers to organizational innovation in healthcare. The first is the lack of good information on quality. Within a market, it is difficult to tell which providers are high quality and which are low quality... Difficulty measuring quality also makes expansion of high-quality firms more difficult [emphasis added]... The second barrier is the stagnant compensation system of public insurance plans."

In a similar vein, Skinner (2011) states in his overview article on regional variations in healthcare:

"[low productivity producers are]... unlikely to be shaken out by normal competitive forces, given the patchwork of providers, consumers and third-party payers each of which faces inadequate incentives to improve quality or lower costs..."

This notion of "healthcare exceptionalism" has a long tradition in health economics. It dates back at least to the seminal article of Arrow (1963), which started the modern field of health economics by emphasizing key features of the health care industry that distinguish it from most other sectors and therefore warrant tailored study.

In this paper, we question this conventional wisdom by investigating empirically whether and to what extent higher quality hospitals tend to attract greater market share. We look at allocation for several different conditions - heart attacks (AMI), congestive heart failure, and pneumonia - as well as allocation for a common pair of surgical procedures - hip and knee replacements - that together account for almost one-fifth of Medicare hospital admissions and hospital spending. We examine a host of key hospital performance, or quality, measures: clinical outcomes (survival and readmission), conformance with processes of care (i.e. adherence to well-established practice guidelines) and ex-post measures of patients' 
satisfaction with their experience (such as whether the room was quiet and whether nurses communicated well).

We find robust evidence that higher performing hospitals - as defined either by the health outcome-based measures or the process of care measures - tend to have greater market share (i.e. more Medicare patients) at a point in time, and experience more growth in market share over time. However, positive responses on patient surveys regarding satisfaction with the hospital stay do not correlate with greater market share. Importantly, our findings of a positive correlation between quality and market share are systematically and substantially stronger among patients who have more scope for choice: that is, within a condition the correlation between hospital quality and allocation is stronger for admissions that are transfers from other hospitals than admissions that come via the emergency room. We interpret these results as consistent with a role for consumer demand - either by patients or their surrogates - to affect the allocation of patients to hospitals. Also, consistent with a role for consumer demand in a setting where there is little if any financial consequence of hospital choice for the patient, we find that conditional on hospital performance, the market does not penalize hospitals with higher inputs - if anything, it rewards them. The normative implications of the reallocation we observe therefore differ for the patient and for a benevolent social planner.

Qualitatively, our results reject an extreme null hypothesis that there are no forces allocating market share to higher quality hospitals. Quantitatively, they suggest an important

role for these reallocation forces. For example, we find that reallocation to higher quality hospitals can explain about 20 percent of the 4.8 percentage point increase in 30-day survival for AMI over the 1996-2008 period. For congestive heart failure and pneumonia - where the secular improvements in survival were only about 1.5 percentage points over this time period - we find a somewhat smaller contribution of reallocation of 14 percent and 7 percent, respectively.

The rest of the paper proceeds as follows. Section 2 describes the analytical framework. Section 3 discusses our setting and data. Section 4 presents our main results on the relationship between hospital quality and market share. Section 5 presents additional evidence consistent with a demand-based mechanism for these allocation results. The last section concludes.

\section{Analytical Approach: Static and Dynamic Allocation}

Our primary empirical exercise examines the correlation between producer (i.e. hospital) performance and market share at a point in time, and the correlation between producer 
performance and growth in market share over time. This relationship has been analyzed extensively in a variety of industries and countries as a proxy for the role of competition in these settings (e.g. Olley and Pakes, 1996; Pavcnik, 2002; Escribano and Guasch, 2005; Bartelsman, Haltiwanger and Scarpetta, 2013; Collard-Wexler and De Loecker, 2013). Intuitively, competitive forces exert pressure on lower productivity firms, causing them to either become more efficient, shrink, or exit.

Models of such reallocation mechanisms among heterogeneous-productivity producers have found applications in a number of fields, including industrial organization, trade, and macroeconomics. ${ }^{1}$ While these models differ considerably in their specifics, they share a common intuition: greater competition - as reflected in greater consumer willingness or ability to substitute to alternative producers - makes it more difficult for higher-cost, lowerproductivity firms to earn positive profits, since demand is more responsive to cost and price differentials across firms. As substitutability increases, purchases are reallocated to higher productivity providers, raising the correlation between productivity and market share at a point in time ("static allocation") and causing higher productivity providers to experience more growth over time ("dynamic allocation").

The literature to date has focused on the relationship between market share and productivity, or the residual of output over costs. However, in the health care setting - and particularly for the Medicare enrollees that are the focus of this study - consumers bear little to none of the costs of production. As a result, it is more sensible to view competition as occurring mainly over output "performance", or quality, rather than productivity per se. In Appendix A we therefore present a model of quality competition among firms that face consumers who are not sensitive to input costs. This model preserves the intuition that consumer ability or willingness to substitute across providers drives the relationship between performance and market allocation. However, in a setting where, due to insurance, consumers have little or no financial stake in their selection, the market need not allocate away from firms that are higher cost for a given level of output.

For the static allocation analysis, we will use the following regression framework:

$$
\ln \left(N_{h}\right)=\beta_{0}+\beta_{1} q_{h}+\gamma_{M}+\varepsilon_{h}
$$

where $N_{h}$ is a measure of the market size of hospital $h, \gamma_{M}$ are market fixed effects, and $q_{h}$ is a measure of the quality of hospital $h$. Thus $\beta_{1}$ reflects the static relationship between a hospital's quality and its market share within a market. If the coefficient is positive, as has been found with respect to productivity in many U.S. manufacturing industries (e.g., Olley

\footnotetext{
${ }^{1}$ See, for example, Ericson and Pakes (1995); Melitz (2003); and Asplund and Nocke (2006).
} 
and Pakes, 1996; Hortaçsu and Syverson, 2007; Bartelsman, Haltiwanger and Scarpetta, 2013), it indicates that higher performance producers have a greater share of activity. If $\beta_{1}$ is zero or negative, it indicates that lower quality facilities are the same size or larger than their high quality counterparts and suggests that forces beyond quality competition are driving the allocation of market activity. In the manufacturing literature, $\beta_{1} \leq 0$ has been found in some former Soviet-bloc countries in the early 1990s (Bartelsman, Haltiwanger and Scarpetta, 2013) and in the U.S. steel industry circa 1960-70 (Collard-Wexler and De Loecker, 2013)..$^{2}$

The static allocation analysis in equation (1) can reflect the market's ability to reallocate activity from low quality hospitals to higher quality ones, but it shows the outcome of this process rather than the process itself. To measure the actual dynamics of the market's selection and reallocation mechanisms, we consider a dynamic metric examining the relationship between hospital quality and its future growth. We will estimate:

$$
\Delta_{h}=\beta_{0}+\beta_{1} q_{h}+\gamma_{M}+\varepsilon_{h}
$$

where $\Delta_{h}$ is a measure of the hospital's growth rate in admissions. A positive correlation between quality and growth indicates that higher performance hospitals see larger gains in patient admissions, and points to the operation of a selection and reallocation process. The productivity literature has found widespread evidence in developed country manufacturing and retail that higher productivity producers experience growth in market shares (e.g. Scarpetta et al., 2002; Disney, Haskel and Heden, 2003; and Foster, Haltiwanger and Krizan, 2006). ${ }^{3}$

Regression equations (1) and (2) form the heart of our empirical analysis. They describe the associations between a hospital's quality and market share and indicate whether forces exist that are favorable to the expansion of higher quality producers. Although motivated by models in which competitive forces create these reallocation pressures, the correlations are naturally not direct evidence of the impact of competition. After presenting our allocation baseline results, we provide evidence consistent with quality competition as a driver of allocation by examining whether the allocation results are stronger among patients who have more scope for hospital choice. We also discuss possible alternative forces that may

\footnotetext{
${ }^{2}$ A positive relationship between producer performance and market share could also reflect increasing returns to scale - increased size could cause performance to rise via e.g. learning by doing. In the health care sector this story is called the "volume-outcome" hypothesis, and we discuss its relationship to our findings in Section 5.2.

${ }^{3}$ An even stronger result from this literature is that low productivity producers are more likely to exit the market entirely (see Bartelsman and Doms, 2000 and Syverson, 2011 for surveys). Hospital exit is poorly measured in our data, so we eschew this analysis and instead look at hospital growth.
} 
mimic the effects of competition, and present evidence suggesting that they are not primarily responsible for the allocation patterns we find in the data.

\section{Setting: Conditions and Quality Measures}

We analyze allocation in health care markets for three conditions and a pair of common surgical procedures: heart attacks (AMI), congestive heart failure (hereafter heart failure or HF), pneumonia, and hip and knee replacement. Together, they account for 17 percent of Medicare hospital admissions and hospital spending in 2008, our base year for analysis. We selected conditions for which the Centers for Medicare and Medicaid Services (CMS) reports a variety of hospital- and condition-specific quality measures. AMI, HF, and pneumonia are the only three inpatient conditions for which CMS reports all of our quality measures in our base year (2008). Since they are predominantly emergency conditions we added hip and knee replacement as the only non-emergency (i.e. deferrable treatment) condition for which one of the quality measures was available. We link these hospital quality measures to data on each hospital's market share in treating the conditions at a point in time and over time. In the remainder of this section we describe first our data on allocation across hospitals and then our quality metrics.

\subsection{Patient Data}

Our primary data set on hospital size and growth consists of all Medicare Part A (i.e., inpatient hospital) claims for all AMI, heart failure, pneumonia, and hip and knee replacement hospital stays occurring in individuals age 66 and over in the United States in 2008 through 2010. We chose 2008 for our base year because it is the first year that all of our quality and allocation metrics could either be calculated by us or were well-populated by CMS. We avoid using more recent years because doing so would limit our ability to study dynamic allocation. In some of our additional analyses below, we use a similar data set spanning 1996 to 2010 to estimate survival (the quality measure we have going back the furthest in time) and allocation over a longer horizon. ${ }^{4}$ These data encompass the universe of Medicare admissions for each of our four conditions for individuals age 66 and over in the United States in these

\footnotetext{
${ }^{4}$ In these data, hospitals that convert to critical access facilities (a program for rural hospitals) or that merge may change their Medicare identifiers and spuriously appear to close. We employ data on hospital identifier changes between 1994 and 2010 and group together all identifiers that ever refer to the same facility into one synthetic hospital. For example, if hospital A merges with hospital B and the two facilities begin sharing an identifier, we treat facilities A and B as one synthetic hospital throughout our analysis. We perform this aggregation for the quality measures as well. We thank Jon Skinner for generously sharing this data with us.
} 
years. The data also contain rich information on patient demographic and health characteristics (called risk adjusters on our context). Risk adjustment helps to address concerns that patient selection of hospitals might bias quality metrics.

Panel A of Table 1a shows the prevalence of each condition in the Medicare population in 2008. The emergency conditions (AMI, heart failure, and pneumonia) are defined based on the patient's principal diagnosis on the reimbursement claim, which indicates the underlying condition that caused the admission to the hospital. Hip and knee replacement patients are defined as patients who received a total hip or knee replacement procedure. Heart failure is the most common (accounting for over half a million patients per year, or 6 percent of Medicare discharges) and AMI is the least common (about a quarter of a million patients per year or about 3 percent of discharges). Over 70 percent of AMI, heart failure, and pneumonia patients are admitted through the emergency room. By contrast, only 2 percent of hip and knee replacement admissions come via the emergency room, which is why we consider this condition non-emergent.

\subsection{Quality metrics}

In choosing our four quality measures, we sought to capture a variety of information about hospitals that might affect the choices of patients or their surrogates. The measures - which are described in more detail in Appendix B - are each drawn from or based on publicly reported hospital-specific quality measures that are currently being used by CMS as the basis for financial incentives for hospitals.

Our first two hospital quality metrics capture condition-specific health outcomes: riskadjusted 30-day survival rates and risk-adjusted 30-day readmission rates. Both are measured for Medicare patients with a given condition at a given hospital. Through the Hospital Value Based Purchasing Program and Readmissions Reduction Program, respectively, CMS is now adjusting its payments to hospitals to reward those that provide high quality care on these two dimensions (Rau, 2013).

Readmission is defined by CMS on a sample of patients that excludes those who die during the initial hospital stay, are transferred from their initial hospital to another inpatient facility, or who leave the hospital against medical advice; these exclusions are designed to remove patients who either could not be readmitted, or whose readmissions might not be due to the hospital's quality of care. Risk-adjusted readmission is the only condition-specific measure which CMS reports for hip and knee replacement; hip and knee surgeries are the second most common surgical conditions to occur before re-hospitalizations in Medicare (Jencks, Williams and Coleman, 2009) and readmission (adjusted for patient risk factors) is a well 
accepted quality metric for hip and knee replacement (e.g. Jencks, Williams and Coleman, 2009; Grosso et al., 2012). In 2015, the hip and knee replacement measure was added to the Readmissions Reduction Program to incentivize facilities to keep patients out of the hospital during recovery (Kahn et al., 2015).

Our third quality measure is a condition-specific "process of care" measure which captures the hospital's conformance with established clinical guidelines for care. Specifically, it measures the shares of eligible patients who received certain evidence-based interventions. The data pertain to all patients irrespective of their insurer, and so are not limited to patients covered by Medicare. The processes "were identified with respect to published scientific evidence and consistency with established clinical-practice guidelines" (Williams et al., 2005). For example, the AMI processes cover the administering of aspirin, ACE inhibitors, smoking cessation advice, $\beta$ blockers, and angioplasty. The measures have been widely analyzed in the medical, health policy, and health economics literature (e.g. Jencks et al., 2000; Jencks, Huff and Cuerdon, 2003; Jha et al., 2007; Werner and Bradlow, 2006; Skinner and Staiger, 2007, 2009). They are also now used to adjust payments, with the Medicare Value Based Purchasing Program rewarding hospitals for high levels and growth in the process measures (Blumenthal and Jena, 2013).

Our final quality measure captures overall (hospital-level) patient satisfaction with the hospital experience on a variety of dimensions, such as whether nurses communicated well or the rooms were quiet. The measures come from the 2008 HCAHPS (Hospital Consumer Assessment of Healthcare Providers and Systems), a survey that hospitals administer to their patients following discharge. All patients are included, not just those covered by Medicare, and unlike the other metrics the results are not disaggregated by health condition. The survey results are processed and reported by CMS; the survey instrument is condensed into 10 measures of the patient's experience and perceived quality of care. CMS performs an adjustment for interview mode (e.g. mail, telephone, etc.) and patient characteristics. Like the process of care measures, high and growing survey scores are now being rewarded by the Value Based Purchasing Program (Blumenthal and Jena, 2013).

The four quality measures capture distinct aspects of hospital performance. Risk-adjusted survival is arguably the key endpoint for emergent conditions, and has been the health outcome of choice for a large economics and medical literature (see e.g. Andersen et al., 2003 for a typical medical trial example, and Cutler et al., 1998 for a classic example of survival as an endpoint in economics and health). Risk adjusted readmission is widely used as a proxy for medical errors and inappropriate discharge (e.g. Anderson and Steinberg, 1984; Axon and Williams, 2011; Jencks, Williams and Coleman, 2009). The process of care measures are designed to measure interventions that the facility should deliver to all appropriate patients; 
the study of processes of care has long been motivated by the concept that hospitals may have more control over them than over health outcomes like survival or readmission, since hospitals have limited influence over which patients they treat and how patients comply with care after discharge (Donabedian, 1966). Patient satisfaction is designed to capture patients' self-reports of ex-post satisfaction with aspects of their hospital experience (Giordano et al., 2010).

\subsection{Summary statistics}

\section{Sample restrictions and potential measurement error in quality measures}

In all of our analyses, we limit the sample for each condition to hospitalizations among patients who have not had an inpatient stay for that condition in the prior year. We call these hospitalizations index events. ${ }^{5}$ We exclude patients who are poorly observed in our data because their Medicare coverage is incomplete (i.e. they failed to enroll in both parts $\mathrm{A}$ and $\mathrm{B}$ of Medicare) or they were enrolled in a private Medicare Advantage plan; these patients cannot be tracked well over time, and so even when we observe their hospitalizations, we cannot assign them to index events. In all of our allocation analyses, we exclude hospitals with no index admission for that condition in 2008. ${ }^{6}$ In addition to the above restrictions which apply to all of our analyses, we make some additional condition- and quality metricspecific restrictions as described below.

The combination of a relatively small number of patients in some hospitals together with the stochastic nature of some of the quality outcomes means that our quality metrics may be estimated with error. Such estimation error may cause attenuation bias in our analysis of the relationship between market share and hospital quality in equations (1) and (2). We take a number of steps to help address this concern. First, in constructing our quality metrics, we aggregate data for our condition-specific quality measures (risk-adjusted survival, riskadjusted readmission, and process of care) over the three-year period 2006-2008. Second, we restrict our sample to hospitals with a minimum number of patients per condition over the three-year measurement period; the cutoff threshold varies across our quality measures

\footnotetext{
${ }^{5}$ Focusing on index events is useful for our allocation exercises because it allows us to think of each observation as an episode of care, treating readmissions and other health expenditures endogenous to the course of treatment in the initial stay as part of that episode rather than as new events. For example, a second admission to the hospital (within a year) for the treatment of an AMI will not count as an index event, so a hospital that frequently readmits its patients will not appear to capture market share as a result.

${ }^{6}$ This restriction introduces a potential concern about selection on the dependent variable (the number of patients in 2008) in the static analysis in equation (1); this is not a concern for the subsequent dynamic analysis. We therefore explored the sensitivity of our static allocation results to an alternative, Tobit-style truncated regression which adjusts for the truncation under a normality assumption. We found that the static allocation results were slightly strengthened by this adjustment (see Appendix Table A1).
} 
as described in Appendix B. For example, for risk-adjusted survival, we follow CMS and restrict to hospitals with at least 25 patients for that condition over 2006-2008.

Third, for our clinical outcomes (survival and re-admission), we apply the standard shrinkage or "smoothing" techniques of the empirical Bayes literature (e.g. Morris, 1983) to adjust for estimation error in our hospital-specific estimates. McClellan and Staiger (1999) introduced this approach into the healthcare literature when estimating quality differences across hospitals, and it has since been widely applied in the education literature for estimating and analyzing teacher or school value added measures (e.g. Kane and Staiger, 2001; Jacob and Lefgren, 2007). The intuition behind it is that when a hospital's quality is estimated to be far above (below) average, it is likely to be suffering from positive (negative) estimation error. Therefore, the expected level of quality, given the estimated quality, is a convex combination of the estimate and the mean of the underlying quality process. The relative weight that the estimate gets in this convex combination varies inversely with the noise of the estimate (which is based on the standard error of the hospital fixed effect). Appendix C provides a detailed description of the procedure. ${ }^{7}$

\section{Static and Dynamic Allocation}

Panels B and C of Table 1a present some summary statistics on our static and dynamic allocation measures, respectively. As discussed, the hospital sample varies by the condition and quality metric; for illustrative purposes we report allocation statistics for the hospitals for which we construct the risk-adjusted survival metric (for the emergency conditions) or risk-adjusted readmission metric (for hip and knee replacement).

For our static allocation analysis in equation (1), our measure of hospital market size $N_{h}$ is the number of Medicare patients with the given condition in 2008 who were treated in hospital $h$-in other words, this is a count of the index events that can be attributed to the hospital. Across the conditions, Panel B shows that the average hospital treated between 66 and 102 Medicare patients in 2008. The standard deviation of hospital size ranges from 68 to $120 .^{8}$

Panel C reports summary statistics on growth in patients from 2008-2010 (i.e. $\Delta_{h}$ ). We define this variable as:

\footnotetext{
${ }^{7}$ In practice, as we show in Appendix Table A2 and Appendix C, our core findings using these quality metrics remain statistically significant without the empirical Bayes adjustment, although naturally the magnitude is attenuated.

${ }^{8}$ Hospital size distributions have a long tail. For example, the 10th size percentile hospital treats 10 AMI patients, the 90 th percentile treats 151 patients, and the 99 th percentile treats 322 patients (not shown).
} 


$$
\Delta_{h}=\frac{N_{h, 2010}-N_{h, 2008}}{\frac{1}{2}\left(N_{h, 2010}+N_{h, 2008}\right)}
$$

where $N_{h, t}$ is the number of Medicare patients with the given condition treated by hospital $h$ in year $t$. Our measure of the hospital's two-year growth rate thus divides the change in the number of patients between the two years by the average number of patients in these two years. ${ }^{9}$ Panel $\mathrm{C}$ shows substantial dispersion in this growth rate across the facilities, with the standard deviation of the measure ranging from 36 to 46 percentage points.

For all the conditions, Panel $\mathrm{C}$ also shows that the average hospital experiences a negative growth in the number of patients between 2008 and 2010. The largest decline occurs for AMI, where the average hospital treats $17 \%$ fewer patients in 2010 compared to 2008, and the smallest occurs for hip and knee replacement, at 3\%. The overall decline in patients reflects three factors. First, there is a secular decline in inpatient admissions overall (not just Medicare) over this time period. ${ }^{10}$ Second, Medicare Advantage, the program that allows Medicare enrollees to receive private insurance, expanded between 2008 and 2010, and these enrollees are excluded from our sample. ${ }^{11}$ Finally, our quality measures require the hospital to have at least 1 patient in 2008 and enough patients in 2006-2008 to calculate the measure accurately (see Appendix B), so regression to the mean will also reduce average growth.

We follow the literature in defining a hospital market as a Hospital Referral Region (HRR). ${ }^{12}$ Our sample includes 306 HRRs. On average, the emergent conditions have 9 to 14 hospitals per HRR while hip and knee replacement has 9 hospitals per HRR. In Appendix Table A3, we show that the great majority (87\%-90\%) of patients stay within their market of residence when receiving treatment for the emergent conditions and a slightly lower share $(84 \%)$ stay in their market for hip and knee replacement.

\footnotetext{
${ }^{9}$ This monotonic transformation of the standard percentage growth rate metric bounds growth between -2 (exit) and +2 (growth from an initial level of 0 ). An attraction of this transformation is that it reduces the chance that the results are skewed by a few fast-growing but initially small hospitals that would have very large percentage growth rates. This growth rate transformation has been used in other contexts to avoid unnecessary skewness in the growth rate measure; see, for example, Davis, Haltiwanger and Schuh (1998).

${ }^{10}$ To show the all-payer decline in inpatients, we used HCUPnet to estimate yearly total hospital discharges for CCS principal diagnosis category codes 100 (AMI), 108 (HF), and 122 (pneumonia) and CCS principal procedure category codes 152 (knee arthroplasty) and 153 (hip arthroplasty). See http://goo.gl/FJ0Nvy and http://goo.gl/zeHg2J for these data.

${ }^{11}$ Between 2008 and 2010, the share of Medicare beneficiaries enrolled in Medicare Advantage grew from $21 \%$ to $25 \%$. We retrieved these statistics from http://kff.org/medicare/state-indicator/ enrollees-as-a-of-total-medicare-population/

${ }^{12}$ The Dartmouth Atlas of Healthcare divides the United States into HRRs, which are determined at the ZIP code level through an algorithm that reflects commuting patterns to major referral hospitals. HRRs, which are akin to empirically defined markets for healthcare, may cross state and county borders. A complete list of HRRs can be found at http://www.dartmouthatlas.org/.
} 


\section{Quality metrics}

Table $1 \mathrm{~b}$ presents basic summary statistics on the quality metrics. It shows clinically and economically meaningful dispersion across hospitals in all of our quality measures.

Panel A shows 30 day survival rates, which range from a hospital-level average of 82 percent for AMI to 89 percent for heart failure; as a non-emergent condition, survival is not considered a relevant metric for hip and knee replacement. The standard deviation of these rates across hospitals ranges from 2 to 3 percentage points after adjusting for patient risk factors, suggesting that some facilities are capable of generating higher survival than others. Panel B shows that average hospital-level readmission rate ranges from 6 percent for hip and knee-replacement to about 21 percent for AMI and heart failure; like survival, the cross-facility standard deviations are 2 to 3 percentage points after adjustment for patient risk factors.

Panel $\mathrm{C}$ reports on the process of care measure. In our allocation results, we combine the condition-specific individual process of care scores into a single composite, standardized (i.e. mean 0 and standard deviation 1), condition-specific score. To give a sense of the metric, we present here for each condition a score that is generated by taking, for each hospital, its average utilization of the condition's processes, then averaging the result across hospitals. The reported score of 0.93 for AMI means that for the average hospital, the average utilization rate across the $6 \mathrm{AMI}$ treatments is $93 \%$. Average compliance with the processes is lower for heart failure (83\%) and pneumonia (88\%). The dispersion in compliance across hospitals is larger than in risk-adjusted survival and readmission - it ranges from 5 percentage points for AMI to 14 percentage points for heart failure.

The patient survey is reported in Panel D. In our allocation regressions, in order to capture the full breadth of questions included in the survey and maximize our ability to detect differences in patient experience, we mimic our approach for the process of care metric and use a standardized (i.e. mean 0, standard deviation 1) composite of all the survey questions. To give a flavor for the measures, Panel D reports the results of one of the questions: a self-reported overall rating of the hospital. The table reports the average score across hospitals when low, medium, and high are valued at 1, 2, and 3 respectively. The average patient at the average hospital gives between a medium and a high rating, and this is true even for the hospital two standard deviations below the average.

We examined the correlation of quality measures across hospitals and conditions. For a given hospital quality measure, hospital quality is strongly positively correlated across conditions (see Appendix Table A4); for example, the within-hospital correlation of riskadjusted readmission between the four conditions ranges from 0.44 to 0.94 .

Table 2 examines the correlation of quality measures within each condition (though as 
stated, the patient survey covers all patients). Higher values of all these quality measures are desirable, except for risk-adjusted readmission. Most of the correlations are of the expected sign: risk-adjusted survival and process of care are positively correlated, and risk adjusted readmission and process of care are negatively correlated. ${ }^{13}$ However the correlations are substantially below 1 , suggesting that these measures may be capturing different dimensions of the hospital experience.

Patient satisfaction does not have a systematic correlation with our other quality measures. As has been found previously in the literature (see e.g. Jha et al., 2008 and Boulding et al., 2011), it is positively correlated with hospital performance as measured by readmission and process of care. However, we find that it is negatively correlated with risk-adjusted survival rates. Though samples are limited to several hundred hospitals, we also find (results not shown) that patient satisfaction tends to be negatively correlated with the Bloom et al. (2012) measure of hospital management quality, while both risk-adjusted survival and process of care scores are positively correlated with hospital management scores. ${ }^{14}$ These ambiguous findings for patient satisfaction are not new to the quality measurement literature, and align with concerns of physicians who question the value of patient satisfaction as an informative measure of hospital quality (Manary et al., 2013).

\section{Allocation Results}

\subsection{Static and Dynamic Allocation}

Table 3 presents our central results on the static and dynamic allocation of patients across hospitals. The left hand panel shows univariate static allocation results based on the estimation of equation (1). These results relate the hospital's log number of patients for a given condition in 2008, $\ln \left(N_{h}\right)$, to its quality in $2008, q_{h}$. Because we include market (HRR) fixed effects, this estimate is within market, relating a hospital's market share of patients with a given condition to its quality relative to other hospitals in its market. We call the results univariate because they consider one quality metric at a time.

We find a statistically significant and positive relationship between hospital quality and market share for three of the four quality metrics (risk-adjusted survival, risk-adjusted readmission, and process of care). This suggests that, within a market, more market share

\footnotetext{
${ }^{13}$ Risk-adjusted survival and risk-adjusted readmission are positively correlated; this ostensibly surprising pattern has been previously documented (see e.g. Gorodeski, Starling and Blackstone, 2010) and at least partly reflects the fact that mortality and readmission are competing risks, since patients who die cannot be readmitted.

${ }^{14}$ There were no clear patterns for hospital readmissions and management scores. We are extremely grateful to Nick Bloom for providing us with these measures, which are available for approximately 300 hospitals.
} 
(patients) tends to be allocated to higher quality hospitals at a point in time. For AMI patients (column 1), our estimates suggest that a 1 percentage point increase in a hospital's risk-adjusted AMI survival rate is associated with a 17 percent higher market share (or equivalently, due to the presence of market fixed effects, $17 \%$ more patients), a 1 percentage point reduction in the hospital's readmission rate is associated with $9 \%$ more patients, and a 1 standard deviation increase in the use of consensus AMI treatments (processes of care) is associated with $32 \%$ more patients; all of these results are statistically significant. For heart failure patients (column 2) results are similar in magnitude and statistical significance. For pneumonia patients (column 3) the results are smaller in magnitude but still statistically significant for risk-adjusted survival and process of care; they are wrong signed but insignificant for risk-adjusted readmission. For hip and knee replacement (column 4) we only observe the risk-adjusted readmission measure, which is statistically significant with the expected sign.

The right hand panel shows univariate dynamic allocation results based on the estimation of equation (2). These estimates examine the within-market relationship between a hospital's quality $q_{h}$ and its subsequent two-year growth $\Delta_{h}$, as defined in equation (3). The results again tend to show a statistically significant positive relationship between hospital quality and market share, with the exception of the patient satisfaction survey. For example, for AMI the results indicate that a 1 percentage point increase in the hospitals's risk-adjusted survival rate is associated with 1.5 percentage points higher growth in AMI patients relative to other hospitals in the same market. A hospital with a 1 percentage point lower risk-adjusted AMI readmission rate would tend to grow its AMI patient load 1.5 percentage points faster than other hospitals in the market, and a 1 standard deviation increase in utilization of AMI processes of care is associated with 4.8 percentage points higher growth; all of these results are statistically significant. The results are similar for the other three conditions - with higher risk-adjusted survival, lower readmission, and better process of care scores associated with greater two-year growth - and they are mostly (but not always) statistically significant.

The patient survey score is an exception to our general finding that higher quality hospitals tend to be larger (in the static allocation results) and grow faster (in the dynamic allocation results) than their peers. We find that patient satisfaction is associated with higher (static) market share and greater growth for hip and knee replacement, though these gradients are not statistically significant. But we find a negative static relationship between the patient satisfaction survey and market share for AMI, heart failure, and pneumonia; for example, hospitals with 1 standard deviation higher patient satisfaction tend to treat $32 \%$ fewer AMI patients than their peers; in the dynamic allocation analysis for these conditions, the correlations between patient satisfaction and quality are either positive and insignificant or wrong-signed and significant - suggesting that higher patient survey values are, if 
anything, associated with lower market share over time..

As we discussed in the previous section, hospitals' scores on the patient satisfaction survey are negatively correlated with some of our other quality metrics, and there is debate over their value as a measure of hospital quality. These facts may explain our findings. Alternatively, the fact that market share appears correlated with the health- or process-of-care measures rather than patient satisfaction could reflect what factors drive the demand of patients or their surrogates; for example, patients may not know or may not value features on the survey such as how quiet rooms are at night. It is also possible that - as the one quality metric that is not condition-specific - the patient satisfaction measure has less relevance for the condition-specific allocation decisions.

To probe a little further on the role of the different quality metrics, we examined multivariate analyses in which the whole vector of quality metrics is included on the right-hand side of equations (1) and (2). Appendix Table A5 reports the results. Not surprisingly, given that these variables are highly correlated (see Table 2), the magnitudes on the individual coefficients often attenuate and (for many of the dynamic analyses) are no longer statistically significant. ${ }^{15}$ Overall, however, they suggest an association between market share and each individual quality measure, conditional on the others, that is qualitatively similar to the unconditional correlations shown in Table 3.

In Appendix Table A7, we consider a related multivariate analysis in which we include measures of quality for all the conditions on the right-hand side of the allocation regressions. Again, we find that multiple quality measures tend to matter. While own-condition quality usually remains a significant predictor of allocation, allocation generally loads onto several conditions' quality measures, and the AMI quality measure is often the most quantitatively important. These results likely reflect that within-hospital quality is highly correlated across conditions (see Table A4), and that our condition-specific quality measures are also each noisy measures of underlying condition quality. The AMI measures may offer relatively more precise signals in comparison to the measures of the other conditions, or they may be more salient to consumers.

We examined the robustness of our main allocation findings in Table 3 along a number of dimensions. As previously discussed, we show our static allocation results are robust to alternative ways of handling the truncation on sample size (see footnote 6 and Appendix Table A1). We also show that our core allocation findings for survival and readmission remain without the empirical Bayes adjustment, although naturally the magnitude is attenuated (see

\footnotetext{
${ }^{15}$ Part of the weakening of the results is also due to the fact that we limit the multivariate analysis in Appendix Table A5 to the subset of hospitals that report all four quality measures. Appendix Table A6 shows that when we run the univariate allocation results on this subset of hospitals, the coefficients are somewhat attenuated relative to our baseline results.
} 
Appendix Table A2); and we also find that our static allocation analysis is not sensitive to an alternative, Poisson regression (see Appendix Table A8).

Finally, we explored the sensitivity of our findings to how we handle risk adjustment. A potential concern with both the survival and readmission quality measures is that they may be capturing heterogeneity in patient health across hospitals; this concern is muted for the process of care measures, which exclude patients who were inappropriate for each standard of care. Fortunately, there exist rich data on the relevant health characteristics of the patients (called risk-adjusters) which we use in creating our survival and readmission metrics. Of course, such risk adjustment is only as good as the observable characteristics on which it is based. Risk adjustment for AMI based on our observables has recently been cross-validated by research exploiting ambulance catchment areas as a source of exogenous variation in the allocation of patients to hospitals (Doyle, Graves and Gruber, 2014). In Appendix Table A9 we show that the results are only slightly affected if we instead use coarser risk adjustment (age/race/sex only) or no risk adjustment at all. These results help mitigate concerns that additional risk adjustment would attenuate or eliminate our findings. Moreover, we showed in previous work that additional risk adjustment with extremely rich data (available for a subset of AMI patients) has little effect on allocation results (Chandra et al., 2013).

\subsection{Benchmarking the magnitude of reallocation}

\subsubsection{Quality vs. distance}

As one way of benchmarking the magnitude of our allocation results, we compared the reallocation of market share associated with higher quality to the reallocation associated with shorter distance between patient and hospital. Distance-to-hospital is a classic hospital attribute that has been extensively analyzed as a measure of hospital "price", with the general finding that individuals consider greater distance to the hospital as a disamenity (see e.g. Luft et al., 1990; Town and Vistnes, 2001; Gaynor and Vogt, 2003). To compare allocation on quality to that on distance, we adapt our static allocation analysis in the spirit of the existing distance-to-hospital choice literature. Specifically, we specify the utility function of consumer $p$ for hospital $h$ as:

$$
U_{p h}=\delta_{p}+\rho_{1} \cdot \text { distance }_{p h}+\rho_{2} \cdot \text { distance }_{p h}^{2}+\theta \cdot q_{h}+\varphi_{p h} .
$$

$U_{p h}$ is the utility of a potential choice, $\delta_{p}$ is a patient-specific effect that drops from the estimation, distance $_{p h}$ is the distance from the patient to the hospital (entering as a quadratic), and $q_{h}$ is the hospital's quality metric. There is also a component of utility that is idiosyncratic to the patient-hospital pair $\varphi_{p h}$. We assume that $\varphi_{p h}$ is distributed type 1 extreme 
value, which means the problem can be readily estimated as a conditional logit, as is standard in the hospital choice literature (e.g. Dranove and Satterthwaite, 2000).

When consumers maximize this utility function, the realized choice probabilities are:

$$
\operatorname{Pr}\left(C_{p}=h\right)=\frac{\exp \left(\rho_{1} \cdot \text { distance }_{p h}+\rho_{2} \cdot \text { distance }_{p h}^{2}+\theta \cdot q_{h}\right)}{\sum_{h^{\prime} \in H_{M(p)}} \exp \left(\rho_{1} \cdot \text { distance }_{p h^{\prime}}+\rho_{2} \cdot \text { distance }_{p h^{\prime}}^{2}+\theta \cdot q_{h^{\prime}}\right)},
$$

where $C_{p}$ indicates the hospital that the patient chose for treatment and $H_{M(p)}$ is the patient's choice set of hospitals; we define the choice set as all hospitals in the patient's hospital market $M(p)$ that treat at least 1 patient with that condition in 2008 and for which we observe the relevant quality metric. Because of our definition of the patient's choice set, our analysis - unlike the allocation analysis in Table 3 - excludes any patient who left her market of residence for treatment. As shown in Appendix Table A10, this restriction excludes 10 to $16 \%$ of patients depending on the condition, but does not affect the basic static allocation results.

Table 4 presents the results from the conditional logit choice model (Appendix Table A11 presents the raw logit coefficients). Across the columns are different health conditions. The rows report the marginal rates of substitution between a given quality metric and distance. The marginal rate of substitution of quality for distance (evaluated at the average distance traveled by patients for that condition) is derived from the conditional logit estimates as:

$$
M R S=\frac{\partial U_{p h} / \partial q_{h}}{\partial U_{p h} / \text { distance }_{p h}}=\frac{\theta}{\rho_{1}+2 \cdot \rho_{2} \cdot \overline{\text { distance }}} .
$$

When the MRS is negative, it implies that the quality measure is a good, i.e. that patients are willing to travel farther to gain access to more quality. When it is positive, it implies that the quality metric is a bad.

Qualitatively, the results are what would be expected from the static allocation analysis: hospital choices are consistent with a willingness to travel longer distances in order to gain access to better health outcomes and processes, but not higher patient survey scores. Quantitatively, the results indicate that the average AMI patient is willing to travel 1.8 more miles (about one-tenth of the standard deviation of distance traveled for AMI) to receive treatment at a hospital with 1 percentage point greater risk-adjusted survival, 1.1 miles for 1 percentage point lower risk-adjusted readmission, and 4.4 miles for 1 standard deviation unit greater use of processes of care. The MRS for the patient survey indicates a willingness to travel 0.3 miles to gain 1 standard deviation unit higher patient satisfaction, but this rate is not statistically significantly different from 0 . The results are qualitatively similar for the other conditions, though magnitudes are often smaller - indicating that for these conditions, 
patients are somewhat less willing to travel additional distance for a given increment in quality.

\subsubsection{Contribution to survival gains}

Another way to benchmark the allocation results is to explore their contribution to the secular improvements in survival gains for individuals hospitalized with these conditions. To do so, we expand our analysis period to track risk-adjusted survival from 1996 through 2008. The conventional wisdom is that the driving forces behind survival gains over this time period are a combination of 'high-tech' and 'low-tech' adoption decisions by hospitals (Cutler, 2005; Chandra and Skinner, 2012). But average survival gains can also come from reallocation of patients toward hospitals that achieve better outcomes. We investigate here the extent to which the observed growth in average survival can be attributed to reallocation to higher quality hospitals as opposed to quality improvements within hospitals.

To investigate the role of reallocation in performance growth, we use the approach of Foster, Haltiwanger and Krizan (2001) and Foster, Haltiwanger and Syverson (2008), which is itself a modification of the decomposition first derived in Baily et al. (1992). Specifically, we decompose the change in the average risk-adjusted 30-day survival in a market as follows:

$$
\begin{aligned}
\Delta \bar{q}_{t}= & \underbrace{\sum_{h \in C_{t}} \theta_{h, t-1} \Delta q_{h, t}}_{\text {within }}+\underbrace{\sum_{h \in C_{t}}\left(q_{h, t-1}-\bar{q}_{t-1}\right) \Delta \theta_{h, t}}_{\text {between }}+\underbrace{\sum_{h \in C_{t}} \Delta q_{h, t} \Delta \theta_{h, t}}_{\text {cross }} \\
& +\underbrace{\sum_{h \in M_{t}} \theta_{h, t}\left(q_{h, t}-\bar{q}_{t-1}\right)}_{\text {entry }}-\underbrace{\sum_{h \in X_{t}} \theta_{h, t-1}\left(q_{h, t-1}-\bar{q}_{t-1}\right)}_{\text {exit }}
\end{aligned}
$$

where $\bar{q}_{t}$ is the market-share-weighted average risk-adjusted 30-day survival across hospitals in the market in year $t$, and $\Delta$ is the difference operator. Thus the left-hand side is the change in weighted average patient survival in the market between two periods. $q_{h, t}$ is the risk-adjusted survival rate for hospital $h$ in year $t$ and $\theta_{h, t}$ is its market share, i.e. the share of patients in the market with the condition who were treated at that hospital. $C_{t}$ is the set of hospitals that were open in both $t-1$ and $t ; M_{t}$ is the set of hospitals that entered the market in $t$, and $X_{t}$ is the set of hospitals that exited the market between $t-1$ and $t .^{16}$

The decomposition in equation (7) divides average survival growth into five terms. The first term, "within", reflects changes in average survival in the market due to survival im-

\footnotetext{
${ }^{16}$ Because measurement error in risk-adjusted survival does not cause bias in any of the terms of this decomposition, we do not empirical-Bayes-adjust the survival measure when computing these metrics.
} 
provements among continuing hospitals holding their market shares constant. These are the survival gains that would have been attained in absence of any reallocation. The remaining terms reflect reallocation effects on average survival in the market. The second term, "between", shows how much of the rise is due to patients reallocating to hospitals that were already of high quality. The middle term, "cross", captures the covariance between gains in survival and gains in market share; it indicates whether hospitals that raised quality also grew their patient loads. The final two terms are, respectively, gains in survival due to entering hospitals having better performance than the previous average and the gains due to lower than average performance hospitals exiting. Any of these five terms could of course be negative if changes in survival, shares, or the composition of hospitals were such as to detract from average survival rates in the market.

To operationalize this decomposition, we look at the long difference between $t=2008$ (our baseline period) and $t-1=1996$. To do this, we replicated our sample selection and risk-adjusted survival measure in the 1996 data. ${ }^{17}$ Thus $\Delta \bar{q}_{t}$ represents the change in risk-adjusted 30-day survival between 2008 and 1996 for the market. After conducting the decomposition for each market, we average each component over all markets weighting by the initial number of patients in the market in 1996. The resulting averages reflect the extent to which each of the five components accounted for survival gains over the 12-year period.

Table 5 displays the results. The first row shows the substantial secular improvement in survival gains for individuals hospitalized with these conditions. Average 30-day survival increased across all HRRs by 4.8 percentage points for AMI, 1.4 percentage points for heart failure, and 1.5 percentage points for pneumonia. The academic literature has focused on progress in AMI-survival - presumably because it is most dramatic - and attributed the improvements to technological progress. The literature has credited medically intensive interventions such as stents and reperfusion therapy and low-cost medical interventions such as aspirin and $\beta$ blockers (Fibrinolytic Therapy Trialists' Collaborative Group, 1994; Keeley and Hillis, 2007; Chandra and Skinner, 2012).

Consistent with this conventional wisdom, we find that within-hospital upgrading in quality accounts for the bulk of the AMI improvements, explaining 80 percent of gains in risk-adjusted AMI survival over our 12 year period. However, we also find a quantitatively important role for reallocation; about 20 percent of the secular improvement in AMI survival can be explained by reallocation toward higher quality hospitals. The cross term explains the bulk of the reallocation gains, although exit and entry also play a role. For example,

\footnotetext{
${ }^{17}$ Specifically, just as in our baseline analysis for 2008 we measure risk-adjusted survival using 2006-2008 data and market share with 2008 patient counts, so for our 1996 analysis we measure risk-adjusted survival using 1994-1996 data and market share with 1996 patient counts. We use the same approach to define the sample and implement the risk-adjustment for the 1996 analysis as for the 2008 analysis.
} 
entry of high-performance hospitals can explain about 0.2 percentage points ( 5 percent) of survival gains, and exit of low-performance hospitals can explain about 0.1 percentage points (about 2 percent) of survival gains. ${ }^{18}$

To put the role of reallocation in AMI survival gains in perspective, it is instructive to note that the 1 percentage point improvement in AMI survival over the 1996-2008 period that we attribute to reallocation is about half of the magnitude of the survival gains attributed to each of two major breakthroughs in AMI treatment: reperfusion and primary angioplasty. The former therapy (including e.g. fibrinolytics), the widespread use of which began in the early 1990s, was shown to raise survival rates by 2 percentage points at 30 days (Fibrinolytic Therapy Trialists' Collaborative Group, 1994); the latter therapy, which diffused over the 1990s, increased AMI survival by 2 percentage points over reperfusion therapy at roughly the 1-month mark (Stone, 2008; Keeley, Boura and Grines, 2003b).

For heart failure and pneumonia - where the secular improvements in survival are noticeably smaller - we find a somewhat smaller contribution of reallocation. Table 5 indicates that reallocation can explain about 15 percent of the 1.4 percentage point secular improvement in heart failure survival and about 7 percent of the 1.5 percentage point improvement for pneumonia.

To explore this mechanism behind this reallocation result more deeply, we use our long survival panel to redo our static and dynamic allocation analysis in equations (1) and (2) for five separate periods: 1996, 1999, 2002, 2005, and 2008. Appendix Table A12 shows the results, which indicate that allocation tends to become more directed toward survival over the sample. AMI has the cleanest such pattern; the magnitudes of both static and dynamic allocation increase monotonically over the sample. Heart failure and pneumonia are noisier, especially for the dynamic allocation, but their overall trends are in the same direction.

Thus the extent to which market allocation aligns with hospital performance appears to be increasing in more recent years. This could be because information about hospital quality and hospital outcomes has become more available to patients and their surrogates; the study sample corresponds to a period in which tools like CMS Hospital Compare made it much easier for patients to ascertain the quality of a hospital, and research on the impact of report cards has found some evidence of consumers responding to information therein (Dranove et al., 2003; Dranove and Sfekas, 2008). Alternatively, patients' willingness or ability to switch among hospitals may have improved for other reasons. For example, the consolidation of either insurers or provider groups may have induced consumers to reallocate

\footnotetext{
${ }^{18}$ Due to our sample constructions, "exit" and "entry" need not be literal hospital entry and exit. They also reflect a reduction in condition-specific sample size below the inclusion cutoff (specifically, at least 25 patients in the three year period used to estimate risk-adjusted survival and at least 1 patient in the final year, see Section 3.2).
} 
to higher quality providers. Clearly, these channels are speculative - we do not have the necessary data to pin down the mechanism in this study, but we see this as a natural and interesting area for future work.

\subsection{Private vs. Social Preferences}

Thus far we have examined the correlation of market share with a variety of "quality" metrics but paid no attention to hospital inputs or costs. Uniquely in the health care sector relative to the rest of the economy, consumers absorb little to none of the costs of their treatment. The Medicare patients we analyze all have insurance with limited cost-sharing, much of which in turn is covered by supplemental (public or private) coverage(MEDPAC, 2012). As a result, an output-based quality metric is likely the relevant one from the perspective of consumer demand; we would not expect patients or their surrogates (family members, physicians, etc.) to substitute away from high cost hospitals.

A benevolent social planner, on the other hand, would want to allocate toward hospitals with high quality (output) conditional on inputs (how the social planner would trade off higher output at the cost of higher inputs would depend on the the social welfare function). We therefore analyze how allocation correlates with productivity, which we define as the hospital's ability to generate survival conditional on the inputs it uses in the treatment process. In the health care sector, these inputs are the resources utilized in the treatment of the patient - labor inputs like physicians and nurses and capital inputs like the operating theater and diagnostic scanners. Since the social planner is concerned about conditional survival while the patient values unconditional survival, there may be a wedge between the privately and socially optimal hospital choice. In this section we study this possibility.

To analyze whether the market re-allocates toward some measure of input-adjusted outcomes, we define a patient-level health production function of the following form:

$$
Y_{p}^{s}=A_{h}\left(\prod_{k} R_{p k}^{\lambda_{k}}\right) X_{p}^{\mu} \Xi_{p} .
$$

where the leading term, $A_{h}$, measures the exponential of total factor productivity (TFP) of hospital $h ; Y_{p}^{s}$ is the output generated by the hospital in treating patient $p$; and $X_{p}$ is a measure of hospital inputs used to treat the patient. All production functions relate outputs to inputs; our particular function uses 30-day survival as a measure of output (in fact, $Y_{p}^{s}$ is technically the exponential of this indicator) and a single index of resources spent on the patient as inputs. ${ }^{19}$ The parameter $\mu$ is the elasticity of 30-day survival with respect to risk-

\footnotetext{
${ }^{19}$ This sort of single-input production function is unusual but convenient; one could reasonably interpret
} 
adjusted inputs. Because patients are inherently heterogeneous, survival may also depend on characteristics of the patient, which could potentially also be correlated with input choices. In addition, the marginal effect of inputs on survival may vary with patient characteristics. To capture both of these effects, we follow the literature and adjust inputs for a vector of observable patient-level risk factors, $R_{p k}$, where $k$ indexes the factors. The risk factors are the same as those used in the calculation of risk-adjusted survival described in Appendix B. Finally, the expression $\Xi_{p}$ is a patient-level error term that accounts for random variations in health outcomes.

The hospital production function model in equation (8) allows variation across hospitals in the marginal health product of inputs but constrains hospitals to have the same elasticity of output with respect to input (i.e., $\mu$ is common across hospitals). Our empirical specification therefore allows the "marginal return to inputs" curve to vary across hospitals, as suggested by Chandra and Staiger (2007) and Garber and Skinner (2008).

Taking logs and using lowercase letters to represent the logarithm of uppercase letters yields our estimating equation for the hospital production function:

$$
y_{p}^{s}=a_{h}+\sum_{k} \lambda_{k} r_{p k}+\mu x_{p}+\xi_{p}
$$

This equation is identical to what we use to estimate risk-adjusted survival (see Appendix B for more details) with one key difference: it controls for logged hospital inputs $x_{p}$. Hospital productivity $a_{h}$ is risk- and resources-adjusted survival - or equivalently, hospital output conditional on inputs (which include patient health inputs, i.e. the risk-adjusters we used previously to construct risk-adjusted survival, as well as resource inputs). The key challenge in calculating productivity is therefore constructing an appropriate measure of hospital resource inputs. We consider two such measures.

Our first input measure is federal expenditures, i.e. total Medicare dollar payments to hospitals for inpatient services used in the treatment of the patient during the first 30 days following the admission. Medicare pays hospitals for each patient stay; its reimbursement for a hospital stay is based on the diagnosis causing the admission, whether the patient has other complicating conditions, the geographic location of the hospital, the type of hospital (e.g. whether it is an academic medical center, whether it serves disproportionately low income patients, etc.) and, to some extent, what is done to the patient in the hospital(MedPAC, 2011). For example, within a given hospital, Medicare reimbursement for an AMI admission will vary depending on the presence of a complicating condition like heart failure or stroke and whether the patient receives various intensive treatments such as a bypass operation; the single input as an index of the use of multiple inputs that go into producing health. 
Medicare spending over the 30 days following the index admission will also depend on whether the patient has multiple hospital stays, as each stay triggers an additional Medicare payment.

Using federal expenditures as our input measure allows us to construct a measure of output (survival) per dollar of federal expenditures. Given the social cost of raising public funds, this is a natural and useful productivity metric. However, it has the disadvantage that it captures variation in inputs coming both from hospital-specific prices and the real resources used by the hospital for treatment. Our second input measure addresses this concern by purging the federal spending measure of pricing variation to create a "resource" measure of inputs. Specifically, we define inputs for a patient as the sum of diagnostic-related group (or DRG) weights during the first 30 days following a heart attack. These DRG weights reflect CMS's assessment of the resources necessary to treat a patient as a function of the patient's comorbidities and procedures received. This approach is standard in the literature as a way of purging measures of care utilization of administrative price variation (see e.g. Skinner and Staiger, 2009; Gottlieb et al., 2010). Nonetheless, it is a highly-imperfect measure of inputs, as it does not reflect actual inputs used but rather CMS-defined expected inputs based on the treatment approach chosen.

We limit our analysis to AMIs. We do this because for the other conditions, the vast majority of patients fall into just one or two DRGs. As a result, for these conditions, there is little useful variation in the input measures for us to exploit, as our two measures are mainly driven by the payment for the initial hospital stay, which is largely a function of the DRG.

We estimate the hospital production function in equation (9) for each input measure using the same sample and risk-adjusters as we used to estimate risk-adjusted survival (described in Appendix B). ${ }^{20}$ Having estimated the production function models for each input measure, we then extract the hospital fixed effects to create our estimates of productivity.

Table 6 examines static and dynamic allocation of AMI patients as a function of these hospital productivity measures (i.e. the $a_{h}$ estimated in equation 9). ${ }^{21}$ Columns 1 and 2 consider static allocation with respect to productivity by the "federal dollars" and "real resources" metrics, respectively. Both results imply that a hospital that can generate 1 percentage point greater survival holding inputs constant (i.e. has 1 percentage point greater

\footnotetext{
${ }^{20}$ Running this model with the federal dollars inputs measure yields $\hat{\mu}=0.035$ (standard error $=0.001$ ). In other words, a 10 percent higher payment to the hospital for treating an AMI patient is associated with a 0.35 percentage point increase $(0.4 \%$ of the hospital average survival rate of 0.82$)$ in the probability of post-AMI 30-day survival. Using the resource-based input measure to estimate the hospital production function yields $\hat{\mu}=0.042$ (standard error $=0.001$ ); increasing resources on a patent by 10 percent is associated with a 0.42 percentage point $(0.5 \%)$ increase in the probability of post-AMI 30 day survival.

${ }^{21}$ We empirical-Bayes-adjust the hospital productivity objects when using them in the regressions of Table 6 so that our coefficients are not biased due to measurement error. The empirical Bayes approach is described in Appendix $\mathrm{C}$ and is identical to our approach for risk-adjusted survival and readmission.
} 
TFP) is expected to be about $18 \%$ larger than other hospitals in its market. Columns 5 and 6 repeat this analysis looking at dynamic allocation; for both measures, we find that having 1 percentage point greater TFP is associated with 1.5 percentage points higher growth in patients between 2008 and 2010, compared to other hospitals in the market.

These results show that market reallocation occurs in the direction of higher productivity hospitals. However, as noted, if patients or their surrogates are making the allocation decision, they should not have reason to penalize hospitals which, conditional on output, are high input utilizers; in other words, they value output, not input-adjusted output or "productivity". The social planner, however, would penalize hospitals that, conditional on output, had higher inputs (costs). We therefore examined the (conditional) correlation between allocation and risk-adjusted survival and risk-adjusted inputs. ${ }^{22}$ The results are consistent with the social planner's goal of rewarding hospitals with high performance after adjusting for inputs. However, the market does not reallocate away from hospitals with higher input use conditional on survival as the social planner would want. ${ }^{23}$

We view this result as illustrating the divergence between the goals of the social planner and the consumer in a market where consumers face few costs. Indeed, it appears that, conditional on output, higher inputs are also associated with greater patient flow, although the magnitude of reallocation based on inputs is substantially smaller than that based on output. ${ }^{24}$ It may be the case that consumers (correctly or not) view inputs conditional on outputs as a signal of unobserved quality, or that they have preferences for high intensity care regardless of its medical value, as has been conjectured to have occurred in the past when hospitals competed on technology in a "medical arms race" (e.g. Kessler and McClellan, 2000). With nearly full insurance for hospital treatment, there is no demand-side force

\footnotetext{
${ }^{22}$ Risk-adjusted input use is defined as the hospital fixed effect from the regression of log-inputs on the patient risk-adjusters and hospital fixed effects. Risk-adjusted survival is defined as it was previously (see Appendix B). As with our productivity estimates, we use an empirical Bayes correction to adjust our estimates of risk-adjusted survival and of risk-adjusted inputs for measurement error; our procedure, described in Appendix Section C.4, accounts for the correlation in measurement error between these two objects.

${ }^{23}$ Columns 3, 4, 7 and 8 show that the market reallocates both to hospitals with higher survival (conditional on inputs) and higher inputs (conditional on survival). The coefficient on productivity can remain positive when used as a single index (columns 1, 2, 5, and 6) because the coefficients on risk-adjusted inputs are smaller than those on risk-adjusted survival and because risk-adjusted inputs are a smaller component of variation in productivity than risk-adjusted survival, since they enter after being multiplied by $\mu \ll 1$.

${ }^{24}$ For example, in the static allocation analysis, column 4 indicates that a 1 standard deviation increase in outputs (i.e. risk-adjusted survival) is associated with a $69 \%$ rise in hospital size, while a 1 standard deviation increase in real resources-based inputs is associated with just a $5 \%$ rise in size. In the static analysis, we find substantially larger reallocation toward inputs measured by federal dollars (column 3) than real resources (column 4), but this difference is an artifact of the CMS payment approach; the Medicare payment formula explicitly pays academic medical centers and safety net hospitals more than other hospitals for the same patient, and these facilities tend to be large, which magnifies the correlation between federal dollars and size. The "real resources" input measure accounts for this concern by using the same DRG weight (our measure of inputs) across all hospitals for each case.
} 
in the market for AMI treatment to counteract these preferences and align the consumer's preferences with those of the social planner. To push back against this consumer insensitivity, in 2015 Medicare is penalizing hospitals that have high costs by adding per-beneficiary spending to the measures it uses to adjust payments in its Value-Based Purchasing Program (Kahn et al., 2015; QualityNet, 2015).

\section{Mechanism}

The previous section showed qualitative and quantitative evidence of reallocation to higher quality hospitals. A natural concern with the results is that they purport to show the results of a reallocation process without giving evidence of a mechanism by which such reallocation can occur. In this section we provide additional evidence consistent with a demand-based mechanism and investigate leading alternative explanations.

\subsection{Evidence of demand-based mechanism}

We view the need to find additional signposts of demand-driven allocation as particularly important given that intuition suggests that there may be little scope for patient choice. In particular, for our three emergency conditions, AMI, heart failure and pneumonia, about three-quarters of admissions come via the emergency department. Indeed, there is a long tradition in health economics - dating back at least to McClellan, McNeil and Newhouse (1994)'s analysis of hospital choice by AMI patients - of using the distance from the patient's residence to the nearest hospital as an instrument for which hospital the patient goes to. How, then, is it plausible that patients' (or their surrogates') demand is playing an allocative role in such emergency situations?

As discussed in Section 2 and Appendix A, a key comparative static of a demand-based allocation mechanism is that as consumer's ability or willingness to substitute across producers increases, the static and dynamic allocation results should grow stronger. To investigate this prediction, we segmented our patients within each condition into two groups with arguably different scope for exercising choice over hospitals based on the manner in which they were admitted as inpatients: through the emergency department (ED) or as a non-emergency transfer from another hospital.

AMI is a condition that demands immediate treatment, and most AMI patients are admitted through the hospital's ED. However, a small but still substantial subset of AMI patients arrive at the hospital after being initially treated and stabilized at another facility. We identify these transfer patients as those whose index inpatient stay for AMI did not 
require an admission through the $\mathrm{ED}$ and which occurred immediately after an encounter at another hospital; in Table 7a we show that they comprise 16\% of the AMI sample - about two-thirds of the AMI patients who are not admitted to the hospital through the ED. ${ }^{25}$ We undertake the same breakdown for heart failure and pneumonia patients, although we have a far smaller share of transfer patients for these conditions. There is effectively no variation in the source of admission for hip and knee replacements - 98\% are non-transfer, non-ED admissions, and so we exclude them from the analysis.

Table 7 a contains two important findings. First, even among patients admitted through the ED - where both intuitively and according to the data there is less scope for choice only half are treated at the nearest hospital. This fact helps illustrate that a demand-based mechanism can exist for these patients, even if their ability to choose a hospital is more constrained: some decisionmaker, whether that is the patient, his family, his doctor, or the ambulance driver, is still exercising active choice for a large share of ED admissions. In other words, the hospital distance instrument of McClellan, McNeil and Newhouse (1994) may be predictive, but does not have an $R^{2}$ of 1 ; there may be some scope for choice even among patients admitted via the ED.

Second, Table 7a provides empirical evidence consistent with our motivating assumption that, within a condition, transfer patients have greater scope for choice than ED patients. The table shows distance traveled by the patient to the hospital, with distance defined as the number of miles between the patient's ZIP code of residence and the hospital's ZIP code. Within a condition, transfer patients travel significantly farther for treatment. For example, the median AMI patient admitted through the ED is treated about 5 miles from the patient's home, while the median AMI transfer patient is treated 34 miles from his home. Relatedly, about 52 percent of AMI patients admitted through the ED are treated at the hospital nearest to them, compared to only 3 percent of AMI transfer patients. The travel distance differentials are similar across ED and transfer patients for the other two emergent conditions.

\footnotetext{
${ }^{25}$ Immediately prior to their index stay, transfer AMI patients had an ED encounter at another facility for any reason (including but not limited to AMI) or an inpatient encounter at another facility that was not for AMI (for example, chest pain). Patients are indexed to the first inpatient hospitalization that indicated AMI as the underlying cause of their admission, and hospitalizations that occur within 1 year of a prior AMI stay are not counted as index events. For these reasons, a given patient's episode of care cannot enter both the ED and the transfer samples. The excluded category of patients from this analysis are the one-third of non-ED AMI patients who are not transfers - Appendix Table A13 shows allocation relationships for these patients, which do tend to be positive. These patients may have been directly admitted to the hospital upon physicians' orders, were admitted to the hospital for some other reason and subsequently experienced an AMI during their stay, or were miscoded in the data. We limit our analysis to transfer patients instead of the full set of non-ED patients because transfer patients more clearly select hospitals for the purpose of AMI treatment.
} 
Motivated by this empirical corroboration that transfer patients have more scope for choice than ED patients, Table $7 \mathrm{~b}$ repeats our static and dynamic allocation analysis separately for ED patients and non-ED transfer patients. Specifically, while the quality metrics are the same as in our baseline analysis of Table 3, to construct the left hand side allocation measures, we use only ED patients or only non-ED transfer patients. ${ }^{26}$ The results in Table $7 \mathrm{~b}$ are consistent with a demand-based mechanism: within a condition, where there is more scope for patient choice - both intuitively and according to the data - the static and dynamic allocation results are substantially and statistically significantly larger. ${ }^{27}$

Focusing first on AMI - which is where we have the largest share of transfer patients - there is a consistent pattern that the gradient between quality and market share is larger for the transfer patients than ED patients both at a point in time (static allocation) and over time (dynamic allocation). For the condition-specific measures, the differences are statistically significant in five of the six comparisons. For example, a hospital with 1 percentage point greater risk-adjusted survival will tend to treat $14 \%$ more ED patients than other hospitals in its market, but the gradient is even greater for transfers, where 1 percentage point higher risk-adjusted survival is associated with $43 \%$ more of these patients. Moreover, a hospital with 1 percentage point greater risk adjusted survival will tend to grow its ED patient load by 0.5 percentage points over the next 3 years, but its transfer patient load will tend to grow by 7 percentage points.

As noted, the share of transfer patients is much smaller for heart failure and especially for pneumonia. Nonetheless, the higher gradient between quality and market share for transfer patients than ED patients continues to hold for heart failure, both in the static and dynamic analysis. For pneumonia, the results are largely insignificantly different between ED and transfer patients - though the lack of transfer patients makes accurately measuring allocation difficult for this population.

\footnotetext{
${ }^{26}$ One potential concern with the static analysis is selection on the dependent variable; the transfer sample is much smaller than the ED sample and transfers appear in roughly one-third to one-half of analysis sample hospitals. We therefore use a fixed effects poisson model in this section to avoid dropping zeroes, keeping a common sample within-condition between the two patient groups. The poisson model coefficients have the same interpretation as our baseline linear regression coefficients (Wooldridge, 2002). Our baseline allocation results are not sensitive to the choice of model (see Appendix Table A8) and our ED vs. transfer results remain even under the linear model, though as expected they are somewhat attenuated due to differential truncation (see Appendix Table A14). Furthermore, Appendix Table A15 shows that we find the same pattern of results if instead we replicate the conditional logit analysis of hospital choice in equation (4) separately for patients admitted through the ED and patients admitted as transfers.

${ }^{27}$ For completeness, we include the patient survey results although we found no allocation toward higher quality by this metric. The patient survey continues to be negatively correlated with static allocation for the three conditions, though this relationship is often weak. Its association with growth in patient loads is mostly positive but imprecisely measured; we find no evidence that this gradient differs between ED and transfer patients.
} 
These findings are consistent with an allocation mechanism based on demand by patients or their surrogates. However, they fall short of showing the specific pathway by which patients know which hospitals offer high quality. This ambiguity is not unique to our study. Indeed, a long-standing question in the field - dating back at least to Arrow (1963) - is how patients can acquire information on provider quality. One possibility is some form of market-learning; hospitals acquire a reputation for good outcomes and this reputation spreads through physicians' professional networks and patients' social networks, where it influences patients and their surrogates to request treatment at hospitals that are better at producing survival. Indeed, in a related setting, Johnson (2011) finds that cardiac specialists who have higher risk-adjusted survival rates for their patients are less likely to stop practicing. She interprets this and related evidence as consistent with a model of market learning by the referring physician. Patients or their family members may also obtain such information themselves; there is some evidence, for example, that patients respond to provider report cards (e.g., Dranove et al., 2003 and Dranove and Sfekas, 2008).

Of course, the presence of active hospital choice by patients or their surrogates does not establish that they are choosing on the basis of hospital outcomes as in our speculative discussion of market learning. It is possible that the correlation between performance and market share reflects omitted factors that independently drive demand and correlate with performance. For example, higher treatment quality hospitals might also have better nonhealth amenities like nicer lobbies, which would in turn influence hospital demand (though our null results with respect to the patient survey would seem to lean against this explanation). Alternatively, high quality hospitals could have better managers who improve both the production process and separately increase demand for the hospital. However, even with

such omitted variables, these explanations rely on a role for patient demand causing the healthcare sector to re-allocate toward higher quality producers.

\subsection{Alternative Explanations}

We consider two key alternative, non-demand based explanations for the allocation results. The first alternative view posits that the results reflect reverse causality. In other words, a positive correlation between a hospital's performance and the number of patients it treats is also consistent with increasing returns to scale, in which causality runs from scale to quality rather than vice versa. This is a general issue for interpreting the static allocation measure in any industry. In the particular context of health care, the "volume-outcome" hypothesis conjectures that treating more patients improves provider performance. Not surprisingly, it has proven challenging to establish empirically whether an observed positive correlation 
between provider volume and outcomes is causal (see e.g. Epstein, 2002 for a discussion of the interpretation difficulties in this literature).

We view the volume-outcomes hypothesis as unable to explain the totality of our results. First, the hypothesis provides no prediction for dynamic allocation: in an environment with increasing returns to scale but without quality-sensitive consumers, better hospitals will tend to be bigger at a point in time, but they do not necessarily grow more over time. Second, the volume-outcomes view cannot explain why patients who have more scope for choice are systematically more likely to choose high quality hospitals. Since we find in Table $7 \mathrm{~b}$ that transfer patients are much more likely to present at high quality facilities than ED patients, even if there are increasing returns to scale, patient preferences appear to drive at least some of the observed allocation.

Second, we consider an alternative "mechanical" explanation in which patients simply go to the nearest hospital without considering performance at all. This hypothesis seems particularly natural given the famous McClellan, McNeil and Newhouse (1994) use of distance as an instrumental variable for which hospital treats a given AMI patient. With mechanical assignment of many patients to the nearest hospital, our static and dynamic allocation results could be produced spuriously if, for example, within a market, more densely populated (e.g. urban) areas have both higher quality hospitals and faster population growth.

In practice, however, this type of strict mechanical allocation rule does not seem able to explain our findings. We produce a counterfactual allocation of patients based on this mechanical allocation rule. Specifically, we assign each patient to his nearest hospital instead of the one at which we observe treatment. This approach substantially alters the allocation of patients across hospitals, since across the four conditions, $44 \%$ to $62 \%$ go to a hospital that is not the closest one in their market (see Appendix Table A3). Importantly, under this counterfactual allocation, our static and dynamic results for the condition-specific quality measures either substantially attenuate or reverse. ${ }^{28}$

\section{Conclusion}

This paper has examined the relationship between firm performance and market allocation in healthcare, focusing specifically on hospital treatment of Medicare patients. We examine

\footnotetext{
${ }^{28}$ We present these results in Appendix Tables A16 and A17. Consider, for example, the static and dynamic allocation results for AMI (column 2 of each table). Compared to the baseline results (column 1 of each table), the static allocation coefficients attenuate by a factor of 8 for risk-adjusted survival and attenuate to statistical insignificance for risk-adjusted readmission and processes of care. For dynamic allocation, the outcomes and process coefficients all attenuate to insignificance. The patient survey continues to have a negative correlation with static and dynamic allocation, though the coefficients attenuate by about one-third.
} 
three conditions and a pair of common surgical procedures - AMI, heart failure, pneumonia, and hip and knee replacement - that together account for almost one-fifth of Medicare hospitalizations and hospital spending. For all of these conditions, we find robust evidence that higher quality hospitals - as measured by risk-adjusted survival, risk-adjusted readmissions, and adherence to well-established clinical practice guidelines - tend to attract greater market share at a point in time and to grow more over time. The one exception to this pattern of reallocation to higher quality hospitals is that hospitals that score better on ex-post measures of patients' satisfaction with their experience (such as whether the room was quiet) do not attract greater market share; as we discussed, there is some debate in the literature over whether patient satisfaction scores are an informative measure of hospital quality (see e.g. Manary et al., 2013).

We provide several ways of quantifying these allocation results. For example, focusing on the AMI condition and the risk-adjusted survival quality metrics, our estimates suggest that, within a market, hospitals with a 1 percentage point higher risk-adjusted AMI survival rate have a 17 percent higher market share at a point in time and a 1.5 percentage point higher growth in market share over the next 2 years. We estimate that AMI patients are willing to travel an additional 1.8 miles (about 0.1 standard deviation of distance traveled) to go to a hospital with a 1 percentage point higher risk-adjusted survival rate. Looking over the 1996-2008 period, we estimate that reallocation is responsible for about 20 percent of the 5 percentage point gain in AMI survival, with the other 80 percent due to within-hospital quality improvements.

We present additional evidence that is consistent with a demand-based mechanism at work. In particular, we use a patient's source of admission to the hospital - as a transfer patient admitted after being stabilized elsewhere compared to a patient admitted through the emergency department - to classify patients who have more or less scope for hospital choice. We find a robust pattern that the relationship between performance and market share - both at a point in time and over time - is stronger within a condition for patients who have greater scope for hospital choice.

Our estimated reallocation relationships stop short of indicating what economic or policy forces could be unleashed to create still greater reallocation to higher quality producers. We see a great opportunity for further work that tries to estimate the causal impact of competition - or other factors - on allocation in healthcare. Another important but challenging area for future work is what policies could encourage reallocation in a manner consistent with the objectives of a benevolent social planner. Consumers face very little, if any, financial consequences of their hospital choice. Consistent with this, we find that while the market re-allocates to higher quality hospitals, conditional on quality it does not re-allocate away 
from higher cost hospitals. Naturally this fact has important normative implications for the social (rather than private) efficiency consequences of the allocation forces we observe. Perhaps in recognition of this wedge between the social planner and the patient, in 2015 Medicare began penalizing hospitals that have high costs (Kahn et al., 2015; QualityNet, 2015).

Taken together, our results suggest that healthcare may have more in common with "traditional" sectors than is commonly recognized in popular discussion and academic research. In this sense, our results are in the same spirit as Skinner and Staiger (2007)'s finding of a common "innovativeness factor" across healthcare and other sectors within a geographic area; they showed that areas of the country that were early adopters of hybrid corn in the 1930s and 1940s were also early adopters of $\beta$ blockers for heart attacks at the beginning of the current century. Such findings suggest that, going forward, research on the determinants of performance in the health care sector may benefit from more attention to the insights, both theoretical and empirical, from research about productivity and allocation in other industries. By the same token, insights from the health care sector may likewise be a useful laboratory for thinking about other industries. A recent series of papers by Bloom, Van Reenen and co-authors have begun to do just this, empirically investigating the role of such factors as management style and labor quality on hospital performance (usually survival rates; see Bloom et al., 2010; Propper and Reenen, 2010; Bloom et al., 2012; McConnell et al., 2013). 


\section{References}

Andersen, Henning R., Torsten T. Nielsen, Klaus Rasmussen, Leif Thuesen, Henning Kelbaek, Per Thayssen, Ulrik Abildgaard, Flemming Pedersen, Jan K. Madsen, Peer Grande, Anton B. Villadsen, Lars R. Krusell, Torben Haghfelt, Preben Lomholt, Steen E. Husted, Else Vigholt, Henrik K. Kjaergard, Leif Spange Mortensen, and DANAMI-2 Investigators. 2003. "A Comparison of Coronary Angioplasty with Fibrinolytic Therapy in Acute Myocardial Infarction." The New England Journal of Medicine, 349(8): 733-42.

Anderson, Gerard F., and Earl P. Steinberg. 1984. "Hospital Readmissions in the Medicare Population." New England Journal of Medicine, 311(21): 1349-1353.

Arrow, Kenneth J. 1963. "Uncertainty and the Welfare Economics of Medical Care." The American Economic Review, 53(5): pp. 941-973.

Asplund, Marcus, and Volker Nocke. 2006. "Firm Turnover in Imperfectly Competitive Markets." The Review of Economic Studies, 73(2): 295-327.

Axon, R. Neal, and Mark V. Williams. 2011. "Hospital readmission as an accountability measure." JAMA, 305(5): 504-505.

Baily, Martin N., Charles Hulten, David Campbell, Timothy Bresnahan, and Richard E. Caves. 1992. "Productivity Dynamics in Manufacturing Plants." Brookings Papers on Economic Activity, Microeconomics, 1992: 187-267.

Bartelsman, Eric J., and Mark Doms. 2000. "Understanding Productivity: Lessons from Longitudinal Microdata." Journal of Economic Literature, 38(3): 569-594.

Bartelsman, Eric J., John C. Haltiwanger, and Stefano Scarpetta. 2013. "CrossCountry Differences in Productivity: The Role of Allocation and Selection." The American Economic Review, 103(1): 305-334.

Bloom, Nicholas, Carol Propper, Stephan Seiler, and John Van Reenen. 2010. "The Impact of Competition on Management Quality: Evidence from Public Hospitals." National Bureau of Economic Research Working Paper 16032.

Bloom, Nicholas, Christos Genakos, Raffaella Sadun, and John Van Reenen. 2012. "Management Practices Across Firms and Countries." National Bureau of Economic Research Working Paper 17850. 
Blumenthal, Daniel, and Anupam B Jena. 2013. "Hospital value-based purchasing." Journal of Hospital Medicine, 8(5): 271-7.

Boulding, William, Seth W Glickman, Matthew P Manary, Kevin A Schulman, and Richard Staelin. 2011. "Relationship between patient satisfaction with inpatient care and hospital readmission within 30 days." The American Journal of Managed Care, 17(1): 41-8.

Chandra, Amitabh, Amy Finkelstein, Adam Sacarny, and Chad Syverson. 2013. "Healthcare Exceptionalism? Productivity and Allocation in the U.S. Healthcare Sector." National Bureau of Economic Research Working Paper 19200.

Chandra, Amitabh, and Douglas O. Staiger. 2007. "Productivity Spillovers in Health Care: Evidence from the Treatment of Heart Attacks." Journal of Political Economy, 115(1): 103-140.

Chandra, Amitabh, and Jonathan Skinner. 2012. "Technology Growth and Expenditure Growth in Health Care." Journal of Economic Literature, 50(3): 645-80.

Collard-Wexler, Allan, and Jan De Loecker. 2013. "Reallocation and Technology: Evidence from the U.S. Steel Industry." National Bureau of Economic Research Working Paper 18739.

Cutler, David M. 2005. Your Money Or Your Life: Strong Medicine for America's Health Care System. Oxford University Press.

Cutler, David M. 2010. "Where Are the Health Care Entrepreneurs?" Issues in Science \& Technology, 27(1): 49-56.

Cutler, David M., Mark McClellan, Joseph P. Newhouse, and Dahlia Remler. 1998. "Are Medical Prices Declining? Evidence from Heart Attack Treatments." The Quarterly Journal of Economics, 113(4): 991-1024.

Davis, Steven J., John C. Haltiwanger, and Scott Schuh. 1998. Job Creation and Destruction. The MIT Press.

Disney, Richard, Jonathan Haskel, and Ylva Heden. 2003. "Restructuring and Productivity Growth in UK Manufacturing." Economic Journal, 113(489): 666-694.

Donabedian, Avedis. 1966. "Evaluating the Quality of Medical Care." The Milbank Quarterly, 44(3): 166-206. 
Doyle, Joseph, John A. Graves, and Jonathan Gruber. 2014. "Paying for Quality in Healthcare." Mimeo.

Dranove, David, and Andrew Sfekas. 2008. "Start Spreading the News: A Structural Estimate of the Effects of New York Hospital Report Cards." Journal of Health Economics, 27(5): 1201-7.

Dranove, David, and Mark A. Satterthwaite. 2000. "The industrial organization of health care markets." In Handbook of Health Economics. Vol. 1B, ed. Anthony J. Culyer and Joseph P. Newhouse, Chapter 20, 1093-1139. Elsevier.

Dranove, David, Daniel Kessler, Mark McClellan, and Mark Satterthwaite. 2003. "Is More Information Better? The Effects of "Report Cards" on Health Care Providers." Journal of Political Economy, 111(3): 555-588.

Elliott, Marc N., Alan M. Zaslavsky, Elizabeth Goldstein, William Lehrman, Katrin Hambarsoomians, Megan K. Beckett, and Laura Giordano. 2009. "Effects of survey mode, patient mix, and nonresponse on CAHPS hospital survey scores." Health Services Research, 44(2, Part I): 501-18.

Epstein, Arnold M. 2002. "Volume and Outcome-It Is Time to Move Ahead." The New England Journal of Medicine, 346(15): 1161-4.

Ericson, Richard, and Ariel Pakes. 1995. "Markov-Perfect Industry Dynamics: A Framework for Empirical Work." The Review of Economic Studies, 62(1): 53-82.

Escribano, Alvaro, and J. Luis Guasch. 2005. "Assessing The Impact Of The Investment Climate On Productivity Using Firm-Level Data: Methodology And The Cases Of Guatemala, Honduras, And Nicaragua." World Bank Policy Research Working Paper 3621.

Fibrinolytic Therapy Trialists' Collaborative Group. 1994. "Indications for fibrinolytic therapy in suspected acute myocardial infarction: collaborative overview of early mortality and major morbidity results from all randomised trials of more than 1000 patients." Lancet, 343(8893): 311-22.

Foster, Lucia, John C. Haltiwanger, and Chad Syverson. 2008. "Reallocation, Firm Turnover, and Efficiency: Selection on Productivity or Profitability?" The American Economic Review, 98(1): 394-425.

Foster, Lucia, John C. Haltiwanger, and C. J. Krizan. 2001. "Aggregate Productivity Growth. Lessons from Microeconomic Evidence." In New Developments in Productivity Analysis. 303-372. National Bureau of Economic Research. 
Foster, Lucia, John C. Haltiwanger, and C. J. Krizan. 2006. "Market Selection, Reallocation, and Restructuring in the U.S. Retail Trade Sector in the 1990s." The Review of Economics and Statistics, 88(4): 748-758.

Garber, Alan M., and Jonathan Skinner. 2008. "Is American Health Care Uniquely Inefficient?" The Journal of Economic Perspectives, 22(4): 27-50.

Gaynor, Martin, and William B. Vogt. 2003. "Competition among Hospitals." The RAND Journal of Economics, 34(4): 764-785.

Giordano, Laura A., Marc N. Elliott, Elizabeth Goldstein, William G. Lehrman, and Patrice A. Spencer. 2010. "Development, implementation, and public reporting of the HCAHPS survey." Medical Care Research and Review, 67(1): 27-37.

Gorodeski, Eiran Z., Randall C. Starling, and Eugene H. Blackstone. 2010. "Are All Readmissions Bad Readmissions?" New England Journal of Medicine, 363(3): 297-298.

Gottlieb, Daniel J., Weiping Zhou, Yunjie Song, Kathryn Gilman Andrews, Jonathan S. Skinner, and Jason M. Sutherland. 2010. "Prices Don't Drive Regional Medicare Spending Variations." Health Affairs, 29(3): 537-43.

Grosso, Laura M., Jeptha P. Curtis, Zhenqiu Lin, Lori L. Geary, Smitha Vellanky, Carol Oladele, Lesli S. Ott, Craig Parzynski, Susannah Bernheim, Lisa G. Suter, Elizabeth E. Drye, and Harlan M. Krumholz. 2012. "Hospital-level 30Day All-Cause Risk-Standardized Readmission Rate Following Elective Primary Total Hip Arthroplasty (THA) And/Or Total Knee Arthroplasty (TKA)." Yale New Haven Health Services Corporation/Center for Outcomes Research \& Evaluation.

Hortaçsu, Ali, and Chad Syverson. 2007. "Cementing Relationships: Vertical Integration, Foreclosure, Productivity, and Prices." Journal of Political Economy, 115(2): 250301.

Jacob, Brian A., and Lars Lefgren. 2007. "What Do Parents Value in Education? An Empirical Investigation of Parents' Revealed Preferences for Teachers." The Quarterly Journal of Economics, 122(4): 1603-1637.

Jencks, Stephen F., Edwin D. Huff, and Timothy Cuerdon. 2003. "Change in the quality of care delivered to Medicare beneficiaries, 1998-1999 to 2000-2001." JAMA, 289(3): 305-12. 
Jencks, Stephen F., Mark V. Williams, and Eric A. Coleman. 2009. "Rehospitalizations among patients in the Medicare fee-for-service program." The New England Journal of Medicine, 360(14): 1418-28.

Jencks, Stephen F., Timothy Cuerdon, Dale R. Burwen, Barbara Fleming, Peter M. Houck, Annette E. Kussmaul, David S. Nilasena, Diana L. Ordin, and David R. Arday. 2000. "Quality of medical care delivered to Medicare beneficiaries: A profile at state and national levels." JAMA, 284(13): 1670-6.

Jha, Ashish K., E. John Orav, Jie Zheng, and Arnold M. Epstein. 2008. "Patients' perception of hospital care in the United States." New England Journal of Medicine, 359(18): 1921-31.

Jha, Ashish K., E. John Orav, Zhonghe Li, and Arnold M. Epstein. 2007. "The inverse relationship between mortality rates and performance in the Hospital Quality Alliance measures." Health Affairs, 26(4): 1104-10.

Johnson, Erin. 2011. "Ability, Learning, and the Career Path of Cardiac Specialists." Mimeo.

Kahn, Charles N., Thomas Ault, Lisa Potetz, Thomas Walke, Jayne Hart Chambers, and Samantha Burch. 2015. "Assessing Medicare's Hospital Pay-For-Performance Programs And Whether They Are Achieving Their Goals." Health Affairs, 34(8): 12811288.

Kane, Thomas J., and Douglas O. Staiger. 2001. "Improving School Accountability Measures." National Bureau of Economic Research Working Paper 8156.

Keeley, Ellen C., and L. David Hillis. 2007. "Primary PCI for myocardial infarction with ST-segment elevation." New England Journal of Medicine, 356(1): 47-54.

Keeley, Ellen C., Judith A. Boura, and Cindy L. Grines. 2003b. "Primary Angioplasty versus Intravenous Thrombolytic Therapy for Acute Myocardial Infarction: A Quantitative Review of 23 Randomised Trials." Lancet, 361(9351): 13-20.

Kessler, Daniel P., and Mark B. McClellan. 2000. "Is Hospital Competition Socially Wasteful?" The Quarterly Journal of Economics, 115(2): 577-615.

Luft, Harold S., Deborah W. Garnick, David H. Mark, Deborah J. Peltzman, Ciaran S. Phibbs, Erik Lichtenberg, and Stephen J. McPhee. 1990. "Does quality influence choice of hospital?" JAMA, 263(21): 2899-906. 
Manary, Matthew P., William Boulding, Richard Staelin, and Seth W. Glickman. 2013. "The patient experience and health outcomes." New England Journal of Medicine, 368(3): 201-3.

McClellan, Mark, and Douglas Staiger. 1999. "The Quality of Health Care Providers." National Bureau of Economic Research Working Paper 7327.

McClellan, Mark, Barbara J. McNeil, and Joseph P. Newhouse. 1994. "Does More Intensive Treatment of Acute Myocardial Infarction in the Elderly Reduce Mortality? Analysis Using Instrumental Variables." JAMA, 272(11): 859-66.

McConnell, K. John, Richard C. Lindrooth, Douglas R. Wholey, Thomas M. Maddox, and Nicholas Bloom. 2013. "Management practices and the quality of care in cardiac units." JAMA Internal Medicine, 173(8): 684-92.

MEDPAC. 2012. "Health Care Spending and the Medicare Program." http://www.medpac. gov/documents/reports/jun12_entirereport.pdf.

Melitz, Marc J. 2003. "The Impact of Trade on Intra-Industry Reallocations and Aggregate Industry Productivity." Econometrica, 71(6): 1695-1725.

Morris, Carl N. 1983. "Parametric Empirical Bayes Inference: Theory and Applications." Journal of the American Statistical Association, 78(381): 47-55.

Olley, G. Steven, and Ariel Pakes. 1996. "The Dynamics of Productivity in the Telecommunications Equipment Industry." Econometrica, 64(6): 1263-97.

Pavcnik, Nina. 2002. "Trade Liberalization, Exit, and Productivity Improvements: Evidence from Chilean Plants." The Review of Economic Studies, 69(1): 245-276.

Propper, Carol, and John Van Reenen. 2010. "Can Pay Regulation Kill? Panel Data Evidence on the Effect of Labor Markets on Hospital Performance." Journal of Political Economy, 118(2): 222-273.

QualityNet. 2015. "Hospital Value-Based Purchasing Overview." https://www.qualitynet. org/dcs/ContentServer?c=Page\&pagename=QnetPublic\%2FPage\%2FQnetTier2\&cid= 1228772039937.

Rau, Jordan. 2013. "Methodology: How Value Based Purchasing Payments Are Calculated." http://khn.org/news/value-based-purchasing-medicare-methodology/. 
Scarpetta, Stefano, Philip Hemmings, Thierry Tressel, and Jaejoon Woo. 2002. "The Role of Policy and Institutions for Productivity and Firm Dynamics: Evidence from Micro and Industry Data." OECD Economics Working Paper 329.

Skinner, Jonathan S. 2011. "Causes and Consequences of Regional Variations in Health Care." In Handbook of Health Economics. Vol. 2, ed. Mark V. Pauly, Thomas G. Mcguire and Pedro P. Barros, 45-93. Elsevier.

Skinner, Jonathan S., and Douglas O. Staiger. 2007. "Technology Adoption from Hybrid Corn to Beta-Blockers." In Hard-to-Measure Goods and Services: Essays in Honor of Zvi Griliches. , ed. Ernst R. Berndt and Charles R. Hulten, 545-570. University of Chicago Press.

Skinner, Jonathan S., and Douglas O. Staiger. 2009. "Technology Diffusion and Productivity Growth in Health Care." National Bureau of Economic Research Working Paper 14865 .

Stone, Gregg W. 2008. "Angioplasty strategies in ST-segment-elevation myocardial infarction: part I: primary percutaneous coronary intervention." Circulation, 118(5): 538-51.

Syverson, Chad. 2011. "What Determines Productivity?" Journal of Economic Literature, 49(2): 326-365.

Town, Robert, and Gregory Vistnes. 2001. "Hospital competition in HMO networks." Journal of Health Economics, 20(5): 733-53.

Werner, Rachel M., and Eric T. Bradlow. 2006. "Relationship between Medicare's hospital compare performance measures and mortality rates." JAMA, 296(22): 2694-702.

Williams, Scott C., Stephen P. Schmaltz, David J. Morton, Richard G. Koss, and Jerod M. Loeb. 2005. "Quality of care in U.S. hospitals as reflected by standardized measures, 2002-2004." New England Journal of Medicine, 353(3): 255-64.

Wooldridge, Jeffrey M. 2002. Econometric Analysis of Cross Section and Panel Data. Econometric Analysis of Cross Section and Panel Data, MIT Press. 


\section{Tables}

Table 1a - Summary Statistics on Distance Traveled and Allocation Metrics across Conditions

\begin{tabular}{|c|c|c|c|c|}
\hline & $(1)$ & $(2)$ & (3) & $(4)$ \\
\hline Condition & AMI & Heart Failure & Pneumonia & Hip/Knee Rpl \\
\hline \multicolumn{5}{|c|}{ Panel A - Composition of all Medicare Discharges in 2008} \\
\hline Number of patients in 2008 & 263,485 & 545,363 & 475,756 & 350,536 \\
\hline Share through Emergency Dept & 0.71 & 0.76 & 0.76 & 0.02 \\
\hline Share of all Medicare discharges & 0.03 & 0.06 & 0.05 & 0.04 \\
\hline Share of Medicare hospital spending & 0.04 & 0.05 & 0.04 & 0.05 \\
\hline Number of hospitals in 2008 & 4,257 & 4,547 & 4,607 & 3,297 \\
\hline \multicolumn{5}{|c|}{ Panel B - Static Allocation: Patients in 2008} \\
\hline Index Events & 190,189 & 308,122 & 354,319 & 267,557 \\
\hline Average No. of Patients & 65.8 & 76.6 & 81.9 & 101.7 \\
\hline Standard Deviation & 67.6 & 78.2 & 70.8 & 118.0 \\
\hline Hospitals & 2,890 & 4,023 & 4,325 & 2,632 \\
\hline Hospitals per Market & 9.4 & 13.1 & 14.1 & 8.6 \\
\hline \multicolumn{5}{|c|}{ Panel C - Dynamic Allocation: Growth in Patients from 2008 to 2010} \\
\hline Average Growth Rate & -0.17 & -0.10 & -0.13 & -0.03 \\
\hline Standard Deviation & 0.42 & 0.38 & 0.36 & 0.46 \\
\hline Hospitals & 2,890 & 4,023 & 4,325 & 2,632 \\
\hline
\end{tabular}

Panel A calculated on 100\% sample of Medicare patients in 2008 and counts all patients with condition, not just the index events that are the subject of the remainder of this study and Panels $B$ and $C$. The sample in Panels $B$ and $C$ is all hospitals that had at least 1 patient in 2008 and had a valid risk-adjusted survival rate (risk-adjusted readmission for hip/knee replacement). There are 306 hospital markets, called Hospital Referral Regions (HRRs). Growth is calculated based on the formula in equation (3) that restricts values to between -2 and 2 . 
Table 1b - Summary Statistics on Quality Metrics across Conditions

\begin{tabular}{|c|c|c|c|c|}
\hline & (1) & (2) & (3) & (4) \\
\hline Condition & AMI & Heart Failure & Pneumonia & Hip/Knee Rpl \\
\hline \multicolumn{5}{|c|}{ Panel A - Risk-Adjusted Survival Rates (30 Days): Patients in 2006-2008 } \\
\hline \multirow{2}{*}{$\begin{array}{l}\text { Average 30-Day Survival Rate } \\
\text { (SD of Risk-Adjusted Measure) }\end{array}$} & 0.82 & 0.89 & 0.88 & \\
\hline & $(0.03)$ & $(0.02)$ & $(0.02)$ & \\
\hline Hospitals in Risk-Adjusted Measure & 2,890 & 4,023 & 4,325 & \\
\hline \multicolumn{5}{|c|}{ Panel B - Risk-Adjusted Readmission Rates (30 Days): Patients in 2006-2008 } \\
\hline \multirow{2}{*}{$\begin{array}{l}\text { Average 30-Day Readmission Rate } \\
\text { (SD of Risk-Adjusted Measure) }\end{array}$} & 0.21 & 0.21 & 0.16 & 0.06 \\
\hline & $(0.03)$ & $(0.02)$ & $(0.02)$ & $(0.02)$ \\
\hline Hospitals in Risk-Adjusted Measure & 2,322 & 3,904 & 4,264 & 2,632 \\
\hline \multicolumn{5}{|c|}{ Panel C - Processes of Care: Shares of Patients Receiving Appropriate Treatments in 2006-2008 } \\
\hline \multirow{2}{*}{$\begin{array}{l}\text { Average Score } \\
\qquad(\mathrm{SD})\end{array}$} & 0.93 & 0.83 & 0.88 & \\
\hline & $(0.05)$ & $(0.14)$ & $(0.07)$ & \\
\hline \multirow{2}{*}{$\begin{array}{l}\text { Hospitals } \\
\text { Average No. of Processes Reported }\end{array}$} & 2,398 & 3,666 & 3,920 & \\
\hline & 4.40 & 3.30 & 6.22 & \\
\hline \multicolumn{5}{|c|}{ Panel D - Patient Survey: Survey Covers All Patients in 2008 (Not Limited to Particular Condition) } \\
\hline \multirow{2}{*}{$\begin{array}{l}\text { Avg Overall Rating (1-3, higher is better) } \\
\text { (SD) }\end{array}$} & 2.53 & 2.53 & 2.53 & 2.53 \\
\hline & $(0.14)$ & $(0.14)$ & $(0.14)$ & $(0.14)$ \\
\hline Hospitals & 3,498 & 3,598 & 3,610 & 3,061 \\
\hline
\end{tabular}

Sample restrictions are specific to the condition and quality metric; see text for more details of the metric definitions and sample restrictions. Summary statistics are reported across hospitals. In Panels $A$ and $B$, the standard deviations are of the risk-adjusted measures and are empirical-Bayes-adjusted to account for measurement error (see Appendix Section C.3.1). In Panel D, the number of hospitals differs across conditions, even though the patient survey metric is not condition-specific, because we calculate the ratings on the subset of hospitals that reported at least 1 patient with the condition in 2008. 
Table 2 - Correlation of Quality Metrics within Condition

\begin{tabular}{|c|c|c|c|c|c|c|c|c|}
\hline \multirow[b]{3}{*}{ Metric } & (1) & (2) & (3) & $(4)$ & (5) & (6) & (7) & (8) \\
\hline & \multicolumn{4}{|c|}{ AMI } & \multicolumn{4}{|c|}{$\mathrm{HF}$} \\
\hline & $\begin{array}{l}\text { Risk-Adj } \\
\text { Survival }\end{array}$ & $\begin{array}{l}\text { Risk-Adj } \\
\text { Readm }\end{array}$ & $\begin{array}{l}\text { Process } \\
\text { of Care Z }\end{array}$ & $\begin{array}{l}\text { Patient } \\
\text { Survey Z }\end{array}$ & $\begin{array}{l}\text { Risk-Adj } \\
\text { Survival }\end{array}$ & $\begin{array}{l}\text { Risk-Adj } \\
\text { Readm }\end{array}$ & $\begin{array}{l}\text { Process } \\
\text { of Care Z }\end{array}$ & $\begin{array}{l}\text { Patient } \\
\text { Survey Z }\end{array}$ \\
\hline \multirow[t]{2}{*}{ Risk-Adjusted Survival } & 1.00 & & & & 1.00 & & & \\
\hline & {$[2,890]$} & & & & {$[4,023]$} & & & \\
\hline \multirow[t]{2}{*}{ Risk-Adjusted Readmission } & 0.03 & 1.00 & & & 0.35 & 1.00 & & \\
\hline & {$[2,322]$} & {$[2,322]$} & & & {$[3,904]$} & {$[3,904]$} & & \\
\hline \multirow[t]{2}{*}{ Process of Care Z-Score } & 0.24 & -0.25 & 1.00 & & 0.17 & -0.15 & 1.00 & \\
\hline & {$[2,346]$} & {$[2,214]$} & {$[2,398]$} & & {$[3,607]$} & {$[3,578]$} & {$[3,666]$} & \\
\hline \multirow[t]{4}{*}{ Patient Survey Z-Score } & -0.06 & -0.26 & 0.18 & 1.00 & -0.18 & -0.36 & 0.01 & 1.00 \\
\hline & {$[2,799]$} & {$[2,293]$} & {$[2,370]$} & {$[3,498]$} & {$[3,447]$} & {$[3,398]$} & {$[3,392]$} & {$[3,598]$} \\
\hline & \multicolumn{4}{|c|}{ Pneumonia } & \multicolumn{4}{|c|}{ Hip/Knee Replacement } \\
\hline & Risk-Adj & Risk-Adj & Process & Patient & Risk-Adj & Risk-Adj & Process & Patient \\
\hline Metric & Survival & Readm & of Care Z & Survey Z & Survival & Readm & of Care Z & Survey Z \\
\hline \multirow[t]{2}{*}{ Risk-Adjusted Survival } & 1.00 & & & & & & & \\
\hline & {$[4,325]$} & & & & & & & \\
\hline \multirow[t]{2}{*}{ Risk-Adjusted Readmission } & 0.08 & 1.00 & & & & 1.00 & & \\
\hline & {$[4,264]$} & {$[4,264]$} & & & & {$[2,632]$} & & \\
\hline \multirow[t]{2}{*}{ Process of Care Z-Score } & 0.08 & -0.18 & 1.00 & & & & & \\
\hline & {$[3,871]$} & {$[3,847]$} & {$[3,920]$} & & & & & \\
\hline \multirow[t]{2}{*}{ Patient Survey Z-Score } & -0.03 & -0.36 & 0.18 & 1.00 & & -0.23 & & 1.00 \\
\hline & {$[3,527]$} & {$[3,503]$} & {$[3,512]$} & {$[3,610]$} & & {$[2,542]$} & & {$[3,061]$} \\
\hline
\end{tabular}

Hospitals used to calculate correlation in brackets. All quality metrics are condition-specific except the patient survey, which is only available for as an all-patient average. Correlations involving risk-adjusted survival and readmission are adjusted to account for measurement error (see Appendix Section C.3.2). 
Table 3 - Allocation across Conditions

\begin{tabular}{|c|c|c|c|c|c|c|c|c|}
\hline \multirow[b]{3}{*}{ Measure $\backslash$ Condition } & (1) & (2) & (3) & (4) & (5) & (6) & (7) & (8) \\
\hline & \multicolumn{4}{|c|}{ Static Allocation } & \multicolumn{4}{|c|}{ Dynamic Allocation } \\
\hline & AMI & $\mathrm{HF}$ & Pneu & Hip/Knee & AMI & $\mathrm{HF}$ & Pneu & Hip/Knee \\
\hline \multirow[t]{2}{*}{ Risk-Adjusted Survival } & 17.496 & 15.360 & 5.140 & & 1.533 & 0.774 & 1.220 & \\
\hline & $(0.995)$ & $(1.320)$ & $(0.777)$ & & $(0.379)$ & $(0.501)$ & $(0.354)$ & \\
\hline Hospitals & 2,890 & 4,023 & 4,325 & & 2,890 & 4,023 & 4,325 & \\
\hline \multirow[t]{2}{*}{ Risk-Adjusted Readmission } & -9.162 & -10.346 & 0.499 & -21.037 & -1.428 & -2.300 & -1.138 & -1.112 \\
\hline & $(1.621)$ & $(1.782)$ & $(1.575)$ & $(2.027)$ & $(0.611)$ & $(0.651)$ & $(0.679)$ & $(0.836)$ \\
\hline Hospitals & 2,322 & 3,904 & 4,264 & 2,632 & 2,322 & 3,904 & 4,264 & 2,632 \\
\hline \multirow[t]{2}{*}{ Process of Care Z-Score } & 0.319 & 0.332 & 0.211 & & 0.048 & 0.043 & 0.026 & \\
\hline & $(0.026)$ & $(0.016)$ & $(0.015)$ & & $(0.010)$ & $(0.009)$ & $(0.009)$ & \\
\hline Hospitals & 2,398 & 3,666 & 3,920 & & 2,398 & 3,666 & 3,920 & \\
\hline \multirow[t]{2}{*}{ Patient Survey Z-Score } & -0.321 & -0.252 & -0.210 & 0.057 & -0.065 & -0.003 & 0.007 & 0.037 \\
\hline & $(0.052)$ & $(0.038)$ & $(0.030)$ & $(0.051)$ & $(0.015)$ & $(0.011)$ & $(0.011)$ & $(0.022)$ \\
\hline Hospitals & 3,498 & 3,598 & 3,610 & 3,061 & 3,498 & 3,598 & 3,610 & 3,061 \\
\hline
\end{tabular}

The static allocation results are estimated using equation (1), a hospital-level regression of log-patients in 2008 on market fixed effects and the quality measure named in the row. The dynamic allocation results are estimated using equation (2), which is an identical regression except for the dependent variable, which is now growth in patients (constrained between -2 and 2) from 2008 to 2010. Standard errors are bootstrapped with 300 replications and are clustered at the market level. Risk-adjusted survival and readmission are reported in percentage points (e.g. a value of 0.1 is 10 percentage points); process of care and patient survey metrics are reported in standard deviation units (e.g. a value of 1 is 1 standard deviation). 
Table 4 - Choice Model of Patient Allocation across Conditions

\begin{tabular}{|c|c|c|c|c|}
\hline Condition & $\begin{array}{c}(1) \\
\text { AMI }\end{array}$ & $\begin{array}{l}(2) \\
\mathrm{HF}\end{array}$ & $\begin{array}{c}(3) \\
\text { Pneu }\end{array}$ & $\begin{array}{c}(4) \\
\text { Hip/Knee Rpl }\end{array}$ \\
\hline Mean Miles to Chosen Hospital & 12.48 & 8.27 & 7.49 & 13.16 \\
\hline SD Miles to Chosen Hospital & 20.06 & 13.25 & 11.92 & 18.85 \\
\hline \multicolumn{5}{|l|}{ Risk-Adjusted Survival } \\
\hline \multirow[t]{2}{*}{ MRS(1 pp risk-adjusted survival, miles) } & -1.793 & -1.029 & -0.378 & \\
\hline & $(0.158)$ & $(0.129)$ & $(0.057)$ & \\
\hline Patients & 165,005 & 275,671 & 317,904 & \\
\hline \multicolumn{5}{|l|}{ Risk-Adjusted Readmission } \\
\hline \multirow[t]{2}{*}{ MRS(1 pp risk-adjusted readmission, miles) } & 1.138 & 1.040 & 0.451 & 2.385 \\
\hline & $(0.173)$ & $(0.122)$ & $(0.109)$ & $(0.268)$ \\
\hline Patients & 158,086 & 274,667 & 317,374 & 222,673 \\
\hline \multicolumn{5}{|l|}{ Process of Care Z-Score } \\
\hline \multirow[t]{2}{*}{ MRS(1 SD process of care, miles) } & -4.418 & -2.238 & -1.325 & \\
\hline & $(0.383)$ & $(0.221)$ & $(0.110)$ & \\
\hline Patients & 158,032 & 270,773 & 309,623 & \\
\hline \multicolumn{5}{|l|}{ Patient Survey Z-Score } \\
\hline \multirow[t]{2}{*}{ MRS(1 SD patient survey, miles) } & 0.324 & -0.093 & 0.036 & -1.604 \\
\hline & $(0.388)$ & $(0.205)$ & $(0.151)$ & $(0.382)$ \\
\hline Patients & 167,429 & 266,915 & 298,185 & 224,451 \\
\hline
\end{tabular}

These regressions present conditional logit choice models of hospital choice as a quadratic of patient distance to the hospital and the hospital's quality measure (see equation 5). Only one quality measure is used at a time, making these univariate models. Distances are from the ZIP code centroid of the patient to the ZIP code centroid of the hospital. Standard errors are analytic and clustered at the market level.

For the survival and readmission rates, the MRS given by equation 6 is divided by 100 to put it into percentage point terms, i.e. an MRS of $x$ indicates that the patient is indifferent between traveling $x$ additional miles and having 1 percentage point greater survival or readmission. For the process of care and patient survey scores, which are z-scores, the MRS of equation 6 is calculated as written; the interpretation of an MRS equal to $x$ is that a patient would be indifferent between traveling $x$ additional miles and gaining 1 standard deviation unit of the quality metric.

The mean and SD miles statistics are taken from the univariate risk-adjusted survival conditional logits (riskadjusted readmission for hip/knee replacement). All MRSs are evaluated at this mean.

The sample is all patients with the condition in 2008 who stayed in their market of residence for treatment. The choice set for a patient is all hospitals in his market that treated at least one patient in 2008 and for which the quality measure exists. Patients who were treated outside their market of residence or who chose hospitals that lacked the quality measure are excluded from the regressions. 
Table 5 - Decomposition of Gains in Survival Over Time

\begin{tabular}{|c|c|c|c|c|c|c|}
\hline \multirow[b]{3}{*}{ Condition } & (1) & (2) & (3) & (4) & (5) & (6) \\
\hline & \multicolumn{3}{|c|}{ Contributions in Pctage Points } & \multicolumn{3}{|c|}{ Contributions as Share of Total } \\
\hline & AMI & $\mathrm{HF}$ & Pneu & AMI & $\mathrm{HF}$ & Pneu \\
\hline Total Change in Wtd Survival & 0.0483 & 0.0141 & 0.0150 & 1.00 & 1.00 & 1.00 \\
\hline Within & 0.0386 & 0.0122 & 0.0140 & 0.80 & 0.86 & 0.93 \\
\hline Between & 0.0000 & -0.0004 & -0.0004 & 0.00 & -0.03 & -0.02 \\
\hline Cross & 0.0067 & 0.0016 & 0.0010 & 0.14 & 0.12 & 0.07 \\
\hline Entry & 0.0023 & 0.0007 & 0.0006 & 0.05 & 0.05 & 0.04 \\
\hline Exit & -0.0007 & 0.0000 & 0.0002 & -0.02 & 0.00 & 0.02 \\
\hline
\end{tabular}

This table decomposes the gains in risk-adjusted survival for the emergent conditions over our full sample window (between 1996 and 2008) using the decomposition shown in equation (7). Columns 1-3 show the contribution of each component to gains in survival in percentage points. Columns 4-6 show the share of total gains that can be attributed to each component. The exit component enters negatively, so a negative value indicates that exit accounts for a gain in survival.

The decomposition is performed for each market, then averaged together weighted by the market's size in 1996. Risk-adjusted survival is calculated from a regression of survival on hospital fixed effects and patient risk-adjusters. A separate regression is run for each of the year groups 1994-1996 and 2006-2008. The hospital effects are considered the hospital's quality metric for the year group's terminal year. 
Table 6 - Allocation of AMI with Respect to AMI Productivity and its Components

\begin{tabular}{|c|c|c|c|c|c|c|c|c|}
\hline \multirow[b]{2}{*}{ Measure } & $(1)$ & $(2)$ & (3) & $(4)$ & $(5)$ & (6) & $(7)$ & $(8)$ \\
\hline & \multicolumn{4}{|c|}{ Static Allocation for AMI } & \multicolumn{4}{|c|}{ Dynamic Allocation for AMI } \\
\hline \multirow[t]{2}{*}{ Productivity (Fed \$) } & 17.637 & & & & 1.491 & & & \\
\hline & $(1.118)$ & & & & $(0.420)$ & & & \\
\hline \multirow[t]{2}{*}{ Productivity (Resources) } & & 17.540 & & & & 1.471 & & \\
\hline & & $(1.013)$ & & & & $(0.386)$ & & \\
\hline \multirow[t]{2}{*}{ Risk-Adjusted In(Fed \$) } & & & 1.447 & & & & 0.246 & \\
\hline & & & $(0.169)$ & & & & $(0.064)$ & \\
\hline \multirow[t]{2}{*}{ Risk-Adjusted In(Resources) } & & & & 0.620 & & & & 0.468 \\
\hline & & & & $(0.406)$ & & & & $(0.162)$ \\
\hline \multirow[t]{2}{*}{ Risk-Adjusted Survival } & & & 17.940 & 19.789 & & & 1.479 & 1.559 \\
\hline & & & $(1.192)$ & $(1.297)$ & & & $(0.446)$ & $(0.441)$ \\
\hline Hospitals & 2,890 & 2,890 & 2,890 & 2,890 & 2,890 & 2,890 & 2,890 & 2,890 \\
\hline
\end{tabular}

This table repeats the analysis of Table 3 but is limited to static and dynamic allocation for AMI. It shows how allocation is related to AMI productivity or its two components (risk-adjusted survival and risk-adjusted log-inputs). Productivity is defined as risk- and inputs-adjusted survival; see Section 4.3 and equation (9). We consider two input measures, "federal expenditures" and "resources", also defined in the text. Standard errors are bootstrapped with 300 replications and are clustered at the market level.

The standard deviation of productivity is 0.03 (Fed $\$$ or Resources), of risk-adjusted log-inputs is 0.22 (Fed $\$$ ) and 0.07 (Resources), and of risk-adjusted survival is 0.04 (this number differs from that of Table $1 \mathrm{~b}$ because it comes from estimating the joint distribution of survival and inputs, not survival alone).

Table 7a - Travel Distance for ED and Non-ED Transfer Patients across Conditions

\begin{tabular}{|c|c|c|c|c|c|c|c|c|}
\hline \multirow{3}{*}{$\begin{array}{l}\text { Condition } \\
\text { Source of admission }\end{array}$} & (1) & $(2)$ & (3) & (4) & (5) & (6) & (7) & (8) \\
\hline & \multicolumn{2}{|c|}{ AMI } & \multicolumn{2}{|c|}{ Heart Failure } & \multicolumn{2}{|c|}{ Pneumonia } & \multicolumn{2}{|c|}{ Hip/Knee Rpl } \\
\hline & $\mathrm{ED}$ & Transfer & ED & Transfer & ED & Transfer & ED & Transfer \\
\hline Share of patients in 2008 & 0.76 & 0.16 & 0.75 & 0.03 & 0.77 & 0.01 & 0.02 & 0.00 \\
\hline Median miles traveled & 5.43 & 33.77 & 5.06 & 30.15 & 5.12 & 25.20 & 5.88 & 29.18 \\
\hline Mean miles traveled & 40.89 & 66.45 & 34.27 & 61.38 & 37.65 & 52.21 & 44.24 & 61.01 \\
\hline Share treated at nearest hospital & 0.52 & 0.03 & 0.53 & 0.07 & 0.54 & 0.12 & 0.50 & 0.14 \\
\hline
\end{tabular}

This analysis considers 2008 patients who were treated at hospitals in the baseline allocation sample (i.e. hospitals with at least 1 patient in 2008). ED patients were admitted through the hospital's emergency department (i.e. have positive emergency room charges). Non-ED transfer patients were admitted directly after a stay at another hospital (i.e. have zero ER charges and had an inpatient stay or ED encounter at a facility other than their index hospital ending on the day of or day before their index admission). Distances are from the ZIP code centroid of the patient to the ZIP code centroid of the hospital. 
Table 7b - Allocation for ED and Non-ED Transfer Patients across Conditions

\begin{tabular}{|c|c|c|c|c|c|c|}
\hline \multirow{3}{*}{$\begin{array}{l}\text { Condition } \\
\text { Source of admission }\end{array}$} & (1) & $(2)$ & (3) & (4) & (5) & (6) \\
\hline & \multicolumn{2}{|c|}{ AMI } & \multicolumn{2}{|c|}{ Heart Failure } & \multicolumn{2}{|c|}{ Pneumonia } \\
\hline & ED & Transfer & ED & Transfer & ED & Transfer \\
\hline Share of patients in 2008 & 0.76 & 0.16 & 0.75 & 0.03 & 0.77 & 0.01 \\
\hline \multicolumn{7}{|l|}{ Risk-Adjusted Survival } \\
\hline \multirow[t]{2}{*}{ Static Allocation } & 14.489 & 42.532 & 15.727 & 50.673 & 7.168 & 14.049 \\
\hline & $(1.022)$ & $(2.609)$ & $(1.586)$ & $(4.664)$ & $(0.983)$ & $(2.941)$ \\
\hline P-value of test for equality & \multicolumn{2}{|c|}{0.000} & \multicolumn{2}{|c|}{0.000} & \multicolumn{2}{|c|}{0.009} \\
\hline Hospitals & 2,881 & 2,881 & 4,023 & 4,011 & 4,325 & 4,275 \\
\hline \multirow[t]{2}{*}{ Dynamic Allocation } & 0.572 & 7.258 & 2.300 & 13.935 & 3.423 & 4.454 \\
\hline & $(0.496)$ & $(1.260)$ & $(0.799)$ & $(2.635)$ & $(1.006)$ & $(1.793)$ \\
\hline P-value of test for equality & \multicolumn{2}{|c|}{0.000} & \multicolumn{2}{|c|}{0.000} & \multicolumn{2}{|c|}{0.562} \\
\hline Hospitals & 1,384 & 1,384 & 1,438 & 1,438 & 1,451 & 1,451 \\
\hline \multicolumn{7}{|l|}{ Risk-Adjusted Readmission } \\
\hline \multirow[t]{2}{*}{ Static Allocation } & -8.128 & -25.550 & -11.265 & -37.988 & -1.647 & 1.089 \\
\hline & $(1.730)$ & $(5.921)$ & $(2.329)$ & $(6.744)$ & $(2.021)$ & $(6.252)$ \\
\hline P-value of test for equality & \multicolumn{2}{|c|}{0.001} & \multicolumn{2}{|c|}{0.000} & \multicolumn{2}{|c|}{0.653} \\
\hline Hospitals & 2,304 & 2,304 & 3,903 & 3,892 & 4,264 & 4,214 \\
\hline \multirow[t]{2}{*}{ Dynamic Allocation } & 0.148 & -1.837 & -1.812 & -11.381 & -0.439 & -2.517 \\
\hline & $(0.704)$ & $(2.034)$ & $(0.994)$ & $(2.727)$ & $(1.419)$ & $(2.965)$ \\
\hline P-value of test for equality & \multicolumn{2}{|c|}{0.285} & \multicolumn{2}{|c|}{0.001} & \multicolumn{2}{|c|}{0.500} \\
\hline Hospitals & 1,342 & 1,342 & 1,434 & 1,434 & 1,445 & 1,445 \\
\hline \multicolumn{7}{|l|}{ Process of Care Z-Score } \\
\hline \multirow[t]{2}{*}{ Static Allocation } & 0.326 & 1.179 & 0.377 & 0.754 & 0.262 & 0.214 \\
\hline & $(0.021)$ & $(0.090)$ & $(0.025)$ & $(0.058)$ & $(0.018)$ & $(0.043)$ \\
\hline P-value of test for equality & \multicolumn{2}{|c|}{0.000} & \multicolumn{2}{|c|}{0.000} & & \\
\hline Hospitals & 2,379 & 2,379 & 3,665 & 3,653 & 3,920 & 3,869 \\
\hline Dynamic Allocation & 0.008 & 0.216 & 0.063 & 0.295 & 0.079 & 0.098 \\
\hline & $(0.021)$ & $(0.045)$ & $(0.027)$ & $(0.053)$ & $(0.024)$ & $(0.042)$ \\
\hline P-value of test for equality & & & & & & \\
\hline Hospitals & 1,360 & 1,360 & 1,433 & 1,433 & 1,428 & 1,428 \\
\hline Patient Survey Z-Score & & & & & & \\
\hline Static Allocation & -0.157 & -0.034 & -0.141 & -0.090 & -0.137 & -0.203 \\
\hline & $(0.035)$ & $(0.072)$ & $(0.032)$ & $(0.060)$ & $(0.028)$ & $(0.057)$ \\
\hline P-value of test for equality & & & & & & \\
\hline Hospitals & 3,498 & 3,498 & 3,598 & 3,586 & 3,610 & 3,559 \\
\hline Dynamic Allocation & 0.019 & 0.052 & 0.038 & 0.012 & -0.002 & 0.008 \\
\hline & $(0.020)$ & $(0.037)$ & $(0.018)$ & $(0.052)$ & $(0.023)$ & $(0.051)$ \\
\hline P-value of test for equality & & & & & & \\
\hline Hospitals & 1,397 & 1,397 & 1,423 & 1,423 & 1,396 & 1,396 \\
\hline
\end{tabular}

This table repeats the analysis of Table 3, but the left hand side of these regressions considers hospital size and growth counting only ED patients in the odd-numbered columns and only non-ED transferred patients in the even-numbered columns. We use a fixed effects poisson model for static allocation to avoid differential truncation between the two patient groups. To make the poisson model analogous to our baseline static allocation model, its regressand is the count of patients, not the logarithm.

The static allocation sample is the baseline analysis sample from Table 3. Poisson sample sizes may differ from baseline sample sizes because markets with one hospital or markets with all zero patient counts are excluded. The dynamic allocation sample is the subset of baseline hospitals with at least one ED patient and non-ED transfer patient in 2008. Standard errors are bootstrapped with 300 replications and are clustered at the market level. 